\title{
Evaluating the effects of elbows and duct size on the accuracy of hand-held Pitot traverse flow measurements
}

Christopher Daniel Shon Paul Judy

West Virginia University

Follow this and additional works at: https://researchrepository.wvu.edu/etd

\section{Recommended Citation}

Judy, Christopher Daniel Shon Paul, "Evaluating the effects of elbows and duct size on the accuracy of hand-held Pitot traverse flow measurements" (2007). Graduate Theses, Dissertations, and Problem Reports. 4310.

https://researchrepository.wvu.edu/etd/4310

This Thesis is protected by copyright and/or related rights. It has been brought to you by the The Research Repository @ WVU with permission from the rights-holder(s). You are free to use this Thesis in any way that is permitted by the copyright and related rights legislation that applies to your use. For other uses you must obtain permission from the rights-holder(s) directly, unless additional rights are indicated by a Creative Commons license in the record and/ or on the work itself. This Thesis has been accepted for inclusion in WVU Graduate Theses, Dissertations, and Problem Reports collection by an authorized administrator of The Research Repository @ WVU. For more information, please contact researchrepository@mail.wvu.edu. 
Evaluating the Effects of Elbows and Duct Size on the Accuracy of Hand-Held Pitot Traverse Flow Measurements

by

Christopher Daniel Shon Paul Judy

Thesis submitted to the College of Engineering and

Mineral Resources

at West Virginia University

in partial fulfillment of the requirements

for the degree of

Master of Science

in

Industrial Hygiene

Steven Guffey, Ph.D., Chair

Warren Myers, Ph.D.

Kenneth Means, Ph.D.

Department of

Industrial and Management Systems Engineering

Morgantown, West Virginia

2007

Keywords: Ventilation, Pitot Traverse Measurement, Duct Flow 


\begin{abstract}
Evaluating the Effects of Elbows and Duct Size on the Accuracy of Hand-Held Pitot Traverse Flow Measurements
\end{abstract}

Christopher Daniel Shon Paul Judy

This study determined the deviations between Pitot traverses performed by traditional hand-held methods and a traverse device designed to hold the Pitot tube perfectly in position, effectively eliminating errors due to yaw, pitch, and insertion point deviations. The hand-held measurements were performed twice by nine different test subjects, while each position was measured with the traverse device five times. Two ten-point traverse measurements were taken at various distances downstream and upstream from a $90^{\circ}$ elbow. Two different-sized ducts were used in the study, a 3.875-inch and a 6.875-inch. Airflows determined from these measurements were compared to the presumed "gold-standard" values for each duct, which is the airflow at the most downstream location measured using the traverse device $\left(\mathrm{Q}_{\mathrm{Ref}}\right)$. The velocity in each duct was set to approximately 4500 FPM.

Results of the hand-held measurements $\left(\mathrm{Q}_{\text {Hand }}\right)$ were surprisingly close to the corresponding values of $\mathrm{Q}_{\text {Ref. }}$. When the averages of the two perpendicular traverses were taken, deviations from $\mathrm{Q}_{\text {Ref }}$ were within $\pm 2.5 \%$ when taken at the most downstream location. Values of $\mathrm{Q}_{\text {Ref }}$ had a coefficient of variation of $0.59 \%$ for the 3.875 -inch duct and $0.34 \%$ for the 6.875 -inch duct. Values of $\mathrm{Q}_{\text {Hand }}$ were within $\pm 5 \%$ of the mean value of $\mathrm{Q}_{\text {Ref }}$ at locations closer to an elbow or a plain duct entry with a mean deviation of $2 \%$. The exception was 1 value of $Q_{\text {Hand }}$ taken at 4D downstream of the elbow that was $8.75 \%$. At the same locations, measurements taken with the traverse device deviated from the mean value of $Q_{\text {Ref }}$ by as much as $5.8 \%$, suggesting that disturbances to airflows due to the elbow and duct inlet were responsible for greater deviations than holding the Pitot tube by hand. This study demonstrates that manually traversing ducts contributes only modest errors in estimating duct airflows, assuming the subject deviations from

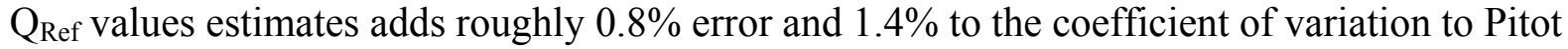
traverse measurements. 


\section{Table of Contents}

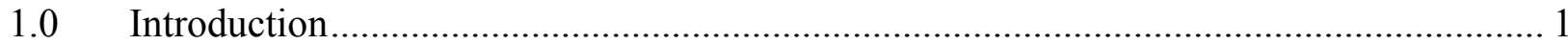

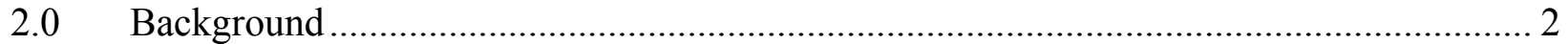

2.1 Use of Velocity Pressure Pitot Traverses to Determine Duct Velocities...............................2

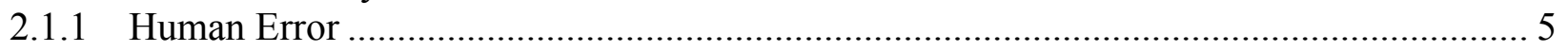

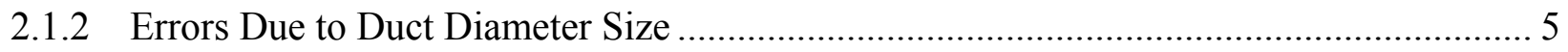

2.1.3 Errors Due to Measurement Location......................................................................... 5

2.1.4 Necessity for Representative Sampling in Measurement ………...................................... 6

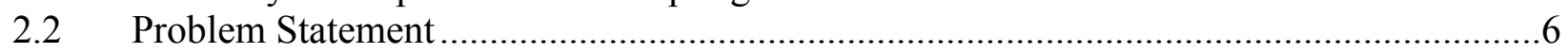

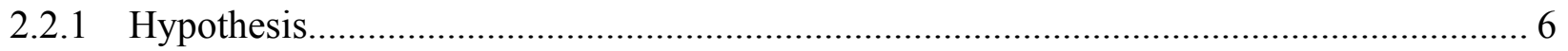

2.2.2 Dependant/Independent Variables ............................................................................. 7

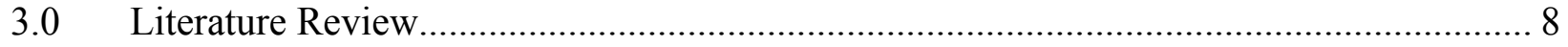

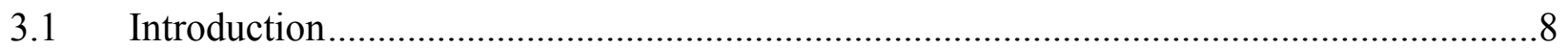

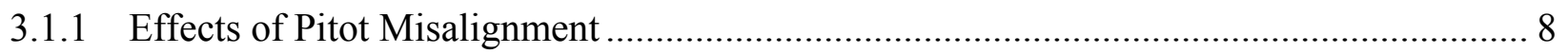

3.1.2 Effects of Upstream Disturbances on Pitot Traverse Measurement Errors ........................ 8

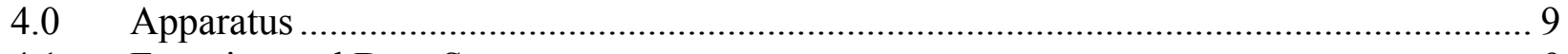

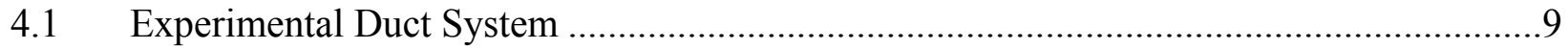

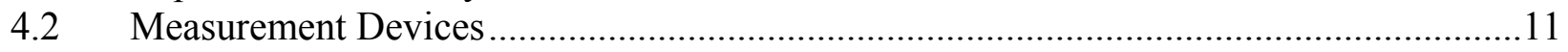

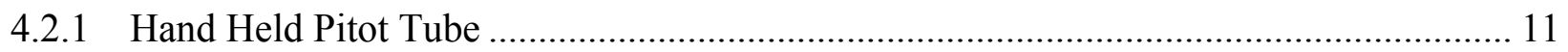

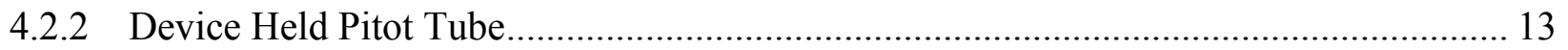

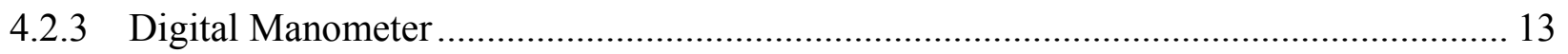

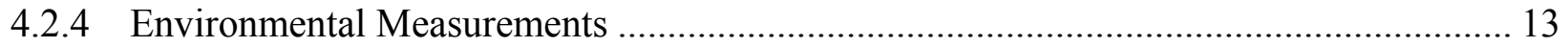

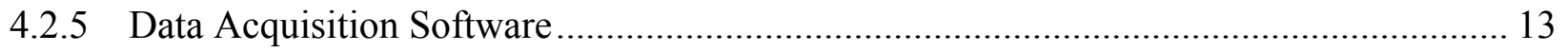

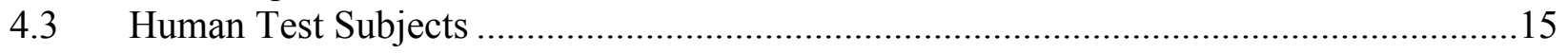

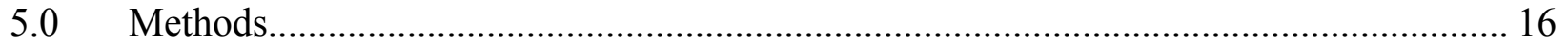

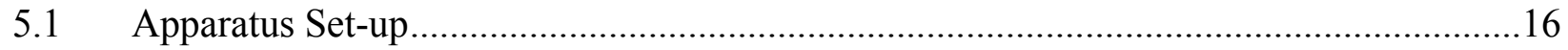

5.2 Conducting Device-Held Pitot Traverse Measurements.......................................................16

5.3 Conducting Hand-Held Pitot Traverse Measurements …….............................................18

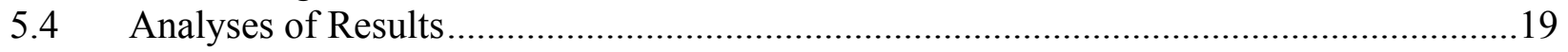

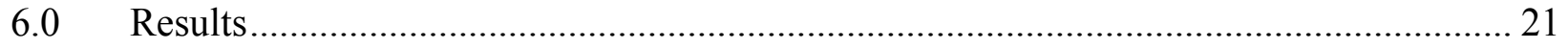

6.1 Measured Velocity Profiles in Ducts ....................................................................21

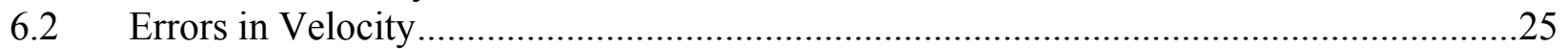

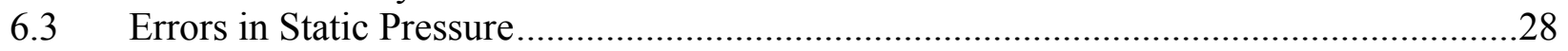

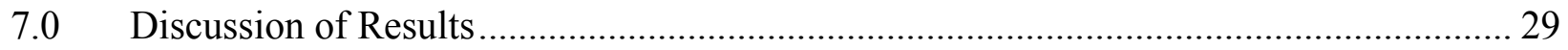

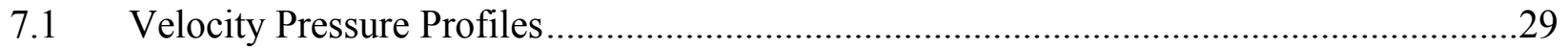

7.2 Errors in Velocity Measurements Due to Location and Duct Size ....................................29

7.3 Errors in Static Pressure Measurements Due to Location and Duct Size ..........................29

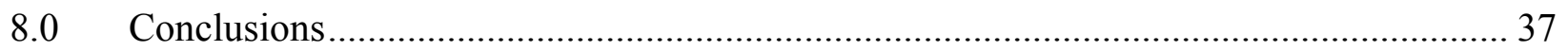

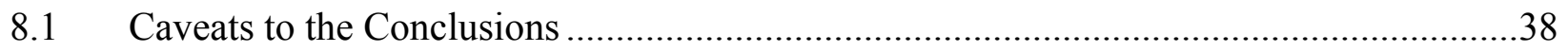

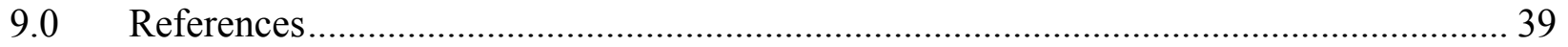

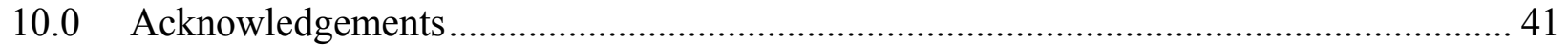

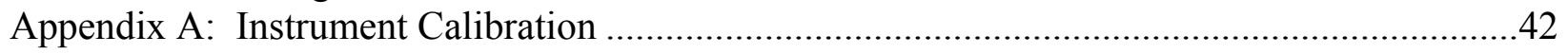

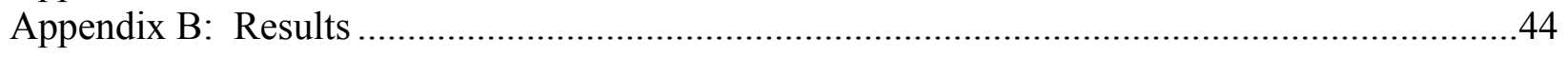




\section{List of Figures}

Figure 1: $\quad$ Standard Pitot Tube Configuration...........................................

Figure 2: $\quad$ Experimental Duct System........................................................

Figure 3: Control Dampers...........................................................

Figure 4: $\quad$ Pitot Tube Holding Device............................................ 12

Figure 5: Traverse Device Measurement........................................... 12

Figure 6: Manometer Display on Computer Screen.......................................14

Figure 7: Velocity Profile....................................................... 14

Figure 8: $\quad$ Pitot Tube, Manometer, and Computer Connected.................................15

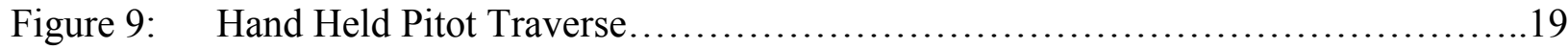

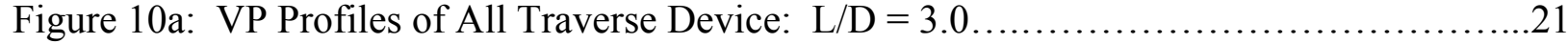

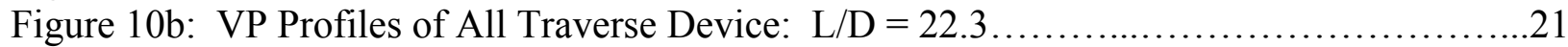

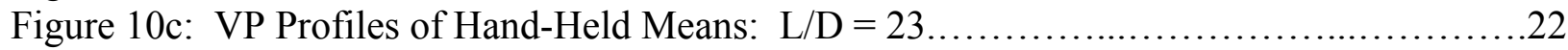

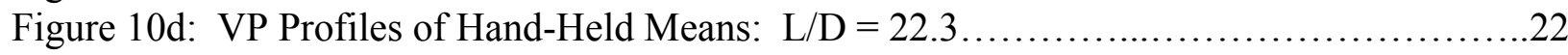

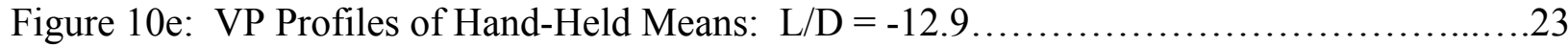

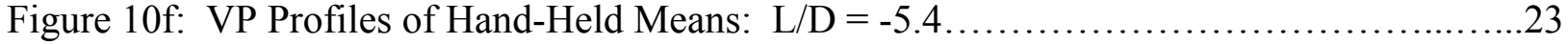

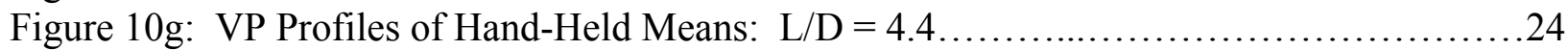

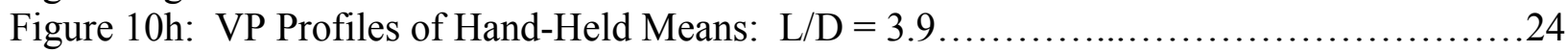

Figure 11: Device Relative Deviation from Reference-Velocity...........................25

Figure 12: Hand-Held Relative Deviation from Reference-Velocity.......................25

Figure 13: Hand-Held Relative Deviation from Device - Velocity ........................26

Figure 14: Hand-Held Relative Deviation from Device — Static Pressure....................27 


\section{$\underline{\text { List of Tables }}$}

Table 1: Location of Traverse Positions along Round Duct Cross-Sections .............................. 6

Table 2: Locations and Distances of Traverse Measurement Sites ....................................... 10

Table 3: Results of Mean Traverse Device and All Hand-Held - Velocity .............................. 26

Table 4: Results of Mean Traverse Device and All Hand-Held—Static Pressure ...................... 28

Table 5: Deviation of Hand from Device 2-Sided Confidence Intervals: Velocity..................... 30

Table 6: Deviation of Hand from Reference 2-Sided Confidence Intervals: Velocity................ 31

Table 7: Deviation of Hand from Device 2-Sided Confidence Intervals: Static Pressure........... 31

Table 8: Deviation of Hand from Device 2-Sided Tolerance Intervals: Velocity ...................... 33

Table 9: Deviation of Hand from Reference 2-Sided Tolerance Intervals: Velocity ................. 33

Table 10: Deviation of Hand from Device 2-Sided Tolerance Intervals: Static Pressure ............ 33

Table 11: Hypothesis Testing of Velocity: Deviation of Hand from Device ............................ 34

Table 12: Hypothesis Testing of Velocity: Deviation of Hand from Reference ....................... 35

Table 13: Hypothesis Testing of Static Pressure: Deviation of Hand from Device ................... 35 


\subsection{Introduction}

It is essential that ventilation systems in workplace environments are evaluated periodically to ensure that they operate efficiently, provide levels of ventilation according to design specifications, and meet applicable agency standards and guidelines. Since monitoring ventilation systems is so important, it is essential that pressure measurements are accurate.

Velocity pressure traverses, using Pitot tubes, are the preferred means of determining the airflow through ducts in ventilation systems. As will be discussed, measurement errors are expected if the probe is incorrectly aligned or inserted. However, it is very common to do this by hand rather than use mechanical jigs or other devices. This study investigated the error contributed by human subjects who each inserted probes by hand in the customary manner. The measurements made by manually holding the probe were compared to measurements made when the probe was held by a mechanical device.

Since accurate velocity measurements are essential for industrial hygienists to evaluate workplace ventilation performance, it is essential that the common method of velocity measurement, hand-held Pitot traverse measurements, be evaluated for its accuracy. The purpose of this research is to determine from the obtained data the degree of accuracy of the hand-held method and to what degree measurement location and duct diameter contribute to errors in velocity determinations. 


\subsection{Background}

\subsection{Use of Velocity Pressure Pitot Traverses to Determine Duct Velocities}

Since air pressure measuring devices, such as manometers, are much easier to calibrate than velocity measurement devices, (Guffey, 1999) it is more practical to determine velocities from measured velocity pressure instead of measuring velocities directly. Also, according to Cheremisinoff, (1988) there is no flow meter commercially available that can directly sense weighted mean velocities.

ANSI/ASHRAE Standard 111-1988 describes the most commonly used, internationally accepted method (ASHRAE, 1988) of establishing the air flow rate in a ventilation system. In this method, one traverses the duct with a Pitot static tube connected to a pressure sensing device, such as a digital manometer. If the Pitot static tube-digital manometer combination is connected to a computer, software can then be used to acquire the data and compute desired calculated values, such as the mean velocity and the airflow.

A Pitot static tube is a tube within a tube. The inner tube is a small diameter tube with a probe that points into the air stream of a duct (see Figure 1). It conducts the pressure (in. w.g.) at the tip of the probe back to a pressure sensor. This inner straight conduit is used to sense total pressure (TP). The outer tube senses static pressure (SP) only. When the TP and SP legs of the Pitot tube are connected to opposite sides of the manometer static pressure forces are equal on both legs. Thus, the difference between the pressures in the two legs is the velocity pressure (VP). Both tubes conduct pressure to pressure-sensing devices, such as an inclined U-tube or a digital manometer.

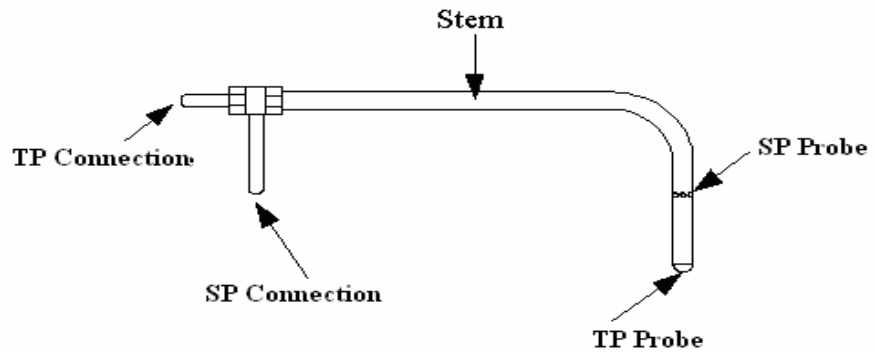

Figure 1: Standard Pitot Tube Configuration

The velocity of air flowing through a duct is generally uniform across the cross-section of the duct. This is especially true if there are obstructions to the airflow upstream of the site of the measurements. Obstructions to duct flow can be caused by elbows in the duct, material that is lodged inside the duct, or dents and any other deformations in the duct. In a uniformly round duct at ideal locations, velocity will be greatest at the center of the duct and decrease towards the inner surface of the duct (Guffey, 1999). This is due to friction slowing the air flowing close to the wall. Ideal air flow location refers to a location along the duct that is seven or more duct diameters from any obstruction to the flow.

Therefore, in order to obtain the average velocity in ducts, a "traverse" of velocity pressure readings must be taken at points of equal area, as is discussed in a following section. 
At least 10 readings should be taken along each of two perpendicular diameters. (ACGIH, 2004) Actual velocities for each area can be calculated from individual velocity pressure readings (see Equation 1)

$$
\begin{aligned}
& V_{i}=4005 \sqrt{\frac{V P_{i}}{d f}} \\
& \sqrt{\frac{V P_{i}}{d f}} \ldots . \\
& \text { Where: } \quad d f=\text { density factor } \\
& V_{i}=\text { velocity, FPM at location (i) } \\
& V P_{i}=\text { velocity pressure, in. w.g. at location (i) }
\end{aligned}
$$

The density factor, $d f$, which is an estimate of actual density divided by the standard density $\left(1.204 \mathrm{~kg} / \mathrm{m}^{3}\right)$, is used to make corrections to measurements when they are not performed at normal temperature and pressure (NTP--293.15 K; $760 \mathrm{~mm} \mathrm{Hg}$ ) and is a function of the humidity mass ratio $(\omega)$, temperature $(\mathrm{t})$, and air pressure $(\mathrm{p})$. The humidity mass ratio is the ratio between the actual mass of water vapor present in moist air to the mass of dry air. The formula for the density factor is stated:

$$
\begin{gathered}
d f=\left(\frac{T_{\text {standard }}}{T_{\text {actual }}}\right)\left(\frac{P_{\text {actual }}+S P_{\text {duct }}}{P_{\text {standard }}}\right)\left(\frac{1+\omega}{1+1.607 \omega}\right) \ldots \ldots \ldots \ldots \ldots \ldots \ldots \ldots \ldots \ldots \ldots \ldots \ldots \\
\text { Where: } \quad s t d=\text { value at } 293.15 \mathrm{~K} \text { and } 760 \mathrm{~mm} \mathrm{Hg} \\
S P_{\text {duct }}=\text { Duct Static Pressure } \\
\omega=\text { Humidity mass ratio }
\end{gathered}
$$

The mean velocity at the cross-section of the duct is calculated from Equation 3. It should also be noted that the centerline velocity pressures are not included in these calculations.

$$
\begin{aligned}
& V=\frac{1}{n} \sum_{i=1}^{n} V_{i} \\
& V_{i}=\text { velocity, FPM at single location (i) } \\
& n=\text { number of samples taken across the area } \\
& \sum \mathrm{V}_{\mathrm{i}}=\text { sum of the velocities }
\end{aligned}
$$

Air flow rate cannot be easily measured directly, so it is calculated using the following Equation 4:

$$
Q=V \times A
$$

Where: $\quad V=$ average velocity at a duct cross-section, FPM

$A=$ area of duct cross-section, $\mathrm{ft}^{2}$

$Q=$ air flow rate, $\mathrm{CFM}$ 
According to Industrial Ventilation, (ACGIH, 2004) the following precautions should be observed to obtain the most accurate measurements:

1. The duct diameter should be at least 30 times the diameter of the Pitot tube.

2. Pitot traverse measurements should be performed at a distance of at least 7 or more duct diameters downstream and 1-1/2 or more diameters upstream of flow obstructions, such as elbows, size changes, or bends.

3. If performing two traverses per measurement ensure that these traverse locations are 90 degrees from each other.

There are several factors which can influence the accuracy of Pitot tube measurements. These include errors due to: the Pitot tube itself; errors due to the pressure sensing device; errors due to misalignment of the Pitot tube to the air flow; instrument errors; Pitot tube alignment errors; errors due to improper insertion depths; human errors; and duct diameter size and measurement location.

The accuracy of Pitot tubes has been tested and published in various publications. The Measurement of Air Flow, $5^{\text {th }}$ edition, states that the calibration factor for the commonlyused hemispherical-nosed Pitot tube has been determined to be between 1.000 and 0.995 with a standard deviation in both cases within \pm 0.001 (Ower and Pankhurst, 1977). This same source also states that instrument errors can be minimized by using Pitot tubes with stems less than $1 / 30^{\text {th }}$ of the duct diameter.

Another source of error is due to the pressure sensor used. Such errors can be minimized by properly zeroing and calibrating the sensor before using it. However, different sensors have different levels of precision, resolution, and linearity. Although sensors with resolutions as much as $1 \times 10^{-6}$ are available such as the 120AD Baratron $^{\mathrm{TM}}$ (MKS; Wilmington, MA), the digital manometers widely used in the field generally contribute errors of less than $0.05 \%$ of the full-scan pressure reading. The Airflow ${ }^{\mathrm{TM}}$ PVM100 (TSI; Buckinghamshire, England) used in this study has a claimed accuracy of $\pm 1 \%$ of reading \pm 1 digit at $20^{\circ} \mathrm{C}$. The pressure resolution of this manometer is $1 \mathrm{~Pa}(0.001$ in. w.g.). This manometer was calibrated by measuring known pressures from 0.0 to 4.0 inches w.g. using a 1425 Hook Gauge from Dwyer Instruments.

It is necessary that the Pitot tube be aligned with the airflow through the duct to achieve accurate measurements. A Pitot tube is properly aligned with the duct when the tube's stem is perpendicular to the duct and its probe is in line with the airflow (see Figure 1). Improper Pitot tube alignment can produce errors in measurements due to the probe not being in line with the air flow. Alignment errors include deviations in yaw and pitch. Yaw is rotation about the stem so that the probe is at an angle to the air flow. A pitch error occurs when the probe and stem are tilted at an angle to the flow. According to Ower and Pankhurst (1977), deviations in yaw and pitch of $20^{\circ}$ contribute errors of $1 \%$, while deviations of $30^{\circ}$ contribute errors of approximately $5 \%$. Since one cannot see the airflow in the duct, there is no better choice than to align the probe with the duct.

Maintaining proper alignment can be a tedious task when multiple measurements are required. Although the Pitot tube itself only weighs a few ounces, it becomes difficult to hold correctly since the user often has to position him or herself in awkward positions while attempting to correctly align the Pitot tube in the duct while inserting it to each of 10 
insertion points. Industrial Ventilation (2004) suggests means to reduce human error, all of which were employed in this study (see Apparatus and Methods).

Another way to eliminate alignment errors is to use a jig that keeps the Pitot tube in place at each of the correct insertion depths. A device described by Guffey (1990) was used in this study to provide a basis of comparison to manually holding the Pitot tube.

\subsubsection{Human Error}

Many errors in measurements can be attributed to the human error. In particular, when inserted manually, it is difficult to hold the probe in-line with duct while the stem is perpendicular to the duct. In addition, unless the Pitot tube is pre-marked, it is difficult to correct judge insertion depths. Finally, hand tremor may introduce error, according to Ower and Pankhurst (1977).

\subsubsection{Errors Due to Duct Diameter Size}

With smaller diameter duct, there is less distance between the insertion points than with larger diameter duct. Therefore, one can assume that with the smaller duct, an insertion point error of, for example, plus or minus one millimeter from the correct insertion point will produce greater errors than a plus or minus one millimeter deviation from the correct insertion point with the larger duct.

\subsubsection{Errors Due to Measurement Location}

The airflow is not always aligned with the duct. In laminar flow conditions, $(\operatorname{Re}<2300)$ the airflow can be regarded as a series of liquid cylinders in the pipe, where the innermost parts flow the fastest, and the cylinder touching the pipe isn't moving at all. In turbulent flow vortices, eddies and wakes make the flow more unpredictable (ACGIH, 2004). More specifically, the airflow will be increasingly misaligned with the duct as the measuring location is closer to a disturbance in the airflow caused by an elbow, a junction fitting, duct entry, or any other disturbance to the flow. At locations that are 50D or greater downstream from these areas of disturbed air flow, the effects are negligible. As demonstrated by Guffey and Booth (1999), at distances closer than 5D, these errors can sometimes exceed 5\% even when mechanical devices are used to carefully insert the Pitot tubes.

Research has shown that the accuracy of mean velocities determined from device-held Pitot traverses are within $2 \%$ under these good conditions (Guffey and Booth, 1999). Two perpendicular traverses at the same cross-section are generally more equal to each other far downstream of disturbances (Cheremisinoff, 1988) so that only one traverse is needed to obtain errors less than 3\% (Guffey and Booth, 1999). 


\subsubsection{Necessity for Representative Sampling in Measurement}

Because flow velocities are not uniform, no single measurement location within a crosssection of a duct can be assumed to have a velocity equal to the average velocity at the cross-section. Therefore, an average of many representative measurements is needed. This is achieved by doing a "traverse" of a diameter, taking measurements at 8 to 10 locations that are midpoints of equal area annular rings. Standards for obtaining traverse measurements can be found in ANSI/ASHRAE Standard 111-1988 (ASHRAE, 1988). Sampling points are based upon the Log Tchebycheff rule for rectangular ducts and the log-linear rule for circular ducts. The more sample points that are measured and the more equally they are distributed across the cross-section of the duct, the more accurate the measurement averages will be. For a round duct, taking two or more traverse measurements will yield a more accurate result than taking one traverse measurement with the same number of sampled points (Guffey, 1999). According to Industrial Ventilation (ACGIH, 2004) the optimum for accuracy for round ducts is eight insertion points along each of three equally separated traverse diameters. Using ten-point traverses along two perpendicular diameters is nearly as accurate and is more convenient to do. These points are determined using the Log-Linear scale found in ANSI/AHRAE 111-1988 (AHRAE, 1988). Table 1 gives the locations, in terms of duct diameters, of the insertion points for traversing round ducts.

Table 1: Location of Traverse Positions along Round Duct Cross-Sections

\begin{tabular}{|c|c|c|c|c|c|c|c|c|c|c|}
\hline $\begin{array}{c}\text { Traverse } \\
\text { Point }\end{array}$ & $\mathbf{1}$ & $\mathbf{2}$ & $\mathbf{3}$ & $\mathbf{4}$ & $\mathbf{5}$ & $\mathbf{6}$ & $\mathbf{7}$ & $\mathbf{8}$ & $\mathbf{9}$ & $\mathbf{1 0}$ \\
\hline $\begin{array}{c}\text { Duct } \\
\text { Diameter } \\
\text { Location }\end{array}$ & 0.019 & 0.077 & 0.153 & 0.217 & 0.361 & 0.639 & 0.783 & 0.847 & 0.923 & 0.981 \\
\hline
\end{tabular}

\subsection{Problem Statement}

The problem to be addressed in this research study was to determine the error in measurements attributable to using customary hand-held Pitot tube methods compared to measurements using a device-held Pitot tube that largely eliminates yaw, pitch, and insertion point errors. The deviations between the two methods are investigated for two different sized ducts (3.875" and 6.875") at 3 sampling locations at different distances from elbows and plain duct entries.

\subsubsection{Hypothesis}

The null hypothesis (see Equations 5a-5c) is that the difference in mean velocities determined by each method is zero. The mean value of velocities measured with the handheld placement by human subjects is $\mu_{H}$ and the mean value of velocities measured using the traverse device is $\mu_{D}$. The mean value of $\mu_{D}$ at the most downstream location is $\mu_{\text {Ref. }}$ 
The alternative hypothesis (see Equations 6a-6d) is that the two velocity measurements are different.

$$
\begin{array}{cl}
\mathrm{H}_{0}: \quad & \mu_{\mathrm{H}}-\mu_{\mathrm{D}}=0 \ldots \\
& \mu_{\mathrm{H}}-\mu_{\mathrm{Ref}}=0 \ldots \\
& \mu_{\mathrm{H}}-\mu_{\mathrm{D}}=0 \ldots \\
& \\
\mathrm{H}_{\mathrm{A}}: \quad & \mu_{\mathrm{H}}-\mu_{\mathrm{D}} \neq 0 \\
& \mu_{\mathrm{H}}-\mu_{\mathrm{Ref}}>0 \\
& \mu_{\mathrm{H}}-\mu_{\mathrm{D}}<> \\
& \mu_{\mathrm{D}}-\mu_{\mathrm{Ref}}>0
\end{array}
$$

Where: $\quad \mu_{\mathrm{H}}=$ Mean for human subjects, hand-held

$\mu_{\mathrm{D}}=$ Mean for traverse device

$\mu_{\text {Ref }}=$ Mean value at Reference location

\subsubsection{Dependant/Independent Variables}

The dependent variables determined in this study are:

- Average velocity in each duct taken at the "ideal" (i.e., most downstream) measurement location using the holding device, $\mathrm{V}_{\text {Ref }}$

- Average velocity at locations of non-ideal conditions, using the traverse device, $\mathrm{V}_{\mathrm{D}}$ or each human subject, $\mathrm{V}_{\mathrm{H}}$

- Difference between the average velocities at each location taken by a human and by the device. $\mathrm{V}_{\mathrm{H}}-\mathrm{V}_{\mathrm{D}}$

- Difference between the average velocities at each location to the value at the corresponding most downstream location taken with the traverse device. $V_{H}-V_{\text {Ref }}$

The independent variables determined in this study are:

- Duct diameter (D): 3.875-inch and 6.875-inch

- Distance of measurement location from the elbow (L) divided by the duct diameter, L/D 


\subsection{Literature Review}

\subsection{Introduction}

The author was unable to find any published research studies that evaluate the accuracy of hand-held Pitot tube measurements. Therefore, in this review the focus will be on published articles which deal with device-held Pitot traverse measurements and their accuracy.

\subsubsection{Effects of Pitot Misalignment}

As mentioned previously, incorrectly positioning a Pitot tube can result in two types of errors: measurement error due to misalignment of flow, and sampling error due to measuring at the wrong insertion points. However, standard Pitot tubes are relatively insensitive to misalignment errors. Research shows that a yaw deviation of $5^{\circ}$ or less will produce only a $3 \%$ velocity error while a deviation of $30^{\circ}$ will produce a velocity error of about 5\% (Ower and Pankhurst, 1977).

\subsubsection{Effects of Upstream Disturbances on Pitot Traverse Measurement Errors}

Guffey and Booth (1999) determined the differences in measurements between Pitot traverses taken under ideal conditions (At least 7D downstream from disturbances) with those taken closer to the same disturbances. They used the same Pitot tube holding devices as used in this study. It was demonstrated in that study that two perpendicular traverses could be taken as close as $2 \mathrm{D}$ downstream from an obstruction and still have errors of $6 \%$ or less. In addition, measurements taken at locations at 3D downstream from an obstruction produced acceptable errors occurring of less than 5\%. This study also compared using single traverses to using two traverses. A single traverse measurement could be accurate at fairly ideal locations: it was found that when using a single traverse, errors seldom exceeded $5 \%$ at distances $6 \mathrm{D}$ or more from the obstruction. This study also found the errors were about the same when measuring high and low velocities from 15004500 FPM. Guffey and Booth speculated that deviation from ideal would have been higher had the Pitot tubes been held by hand (Guffey and Booth 1999). 


\subsection{Apparatus}

This study was done in the Ventilation and Exposure Assessment Laboratory at West Virginia University using the apparatus described in following sections.

\subsection{Experimental Duct System}

A 3.875-inch diameter branch duct along with a 6.875-inch diameter branch duct was used to construct the experimental duct system (see Figure 2). Each branch duct had a $90^{\circ}$ elbow. The turn radius of the 3.875-inch duct elbow was 7 inches with a relative radius of curvature $(\mathrm{R} / \mathrm{D})$ of 1.8 while the turn radius of the 6.875 -inch duct elbow was 5.5 -inches $(\mathrm{R} / \mathrm{D}=0.8)$. Measurement locations were set up along both ducts at the following locations: 4 duct diameters downstream from the plain ends, 3 duct diameters downstream from the elbows, and 21 duct diameters from the same elbows. The measurement locations were roughly the same in terms of duct diameter so that comparisons can be made between the two duct sizes. At each of the three locations for both of the ducts, holes $90^{\circ}$ apart on the circumference of each duct were drilled to allow the insertion of the Pitot tubes to accommodate two perpendicular traverses for each location. Table 2 and Figure 2 show the distances from each traverse measuring point to the duct elbow (L) and also the distances from the elbow of the duct divided by the duct diameter (L/D). The measurements closest to the ends of the ducts $\left(\mathrm{L} / \mathrm{D}_{4}\right.$ "'duct $=-12.9$ and $\mathrm{L} / \mathrm{D}_{7}$ "'duct $\left.=-5.4\right)$ took place at different distances relative from the elbow. However, these same locations were equal to each other in terms of distance from the plain ends (4D from End).

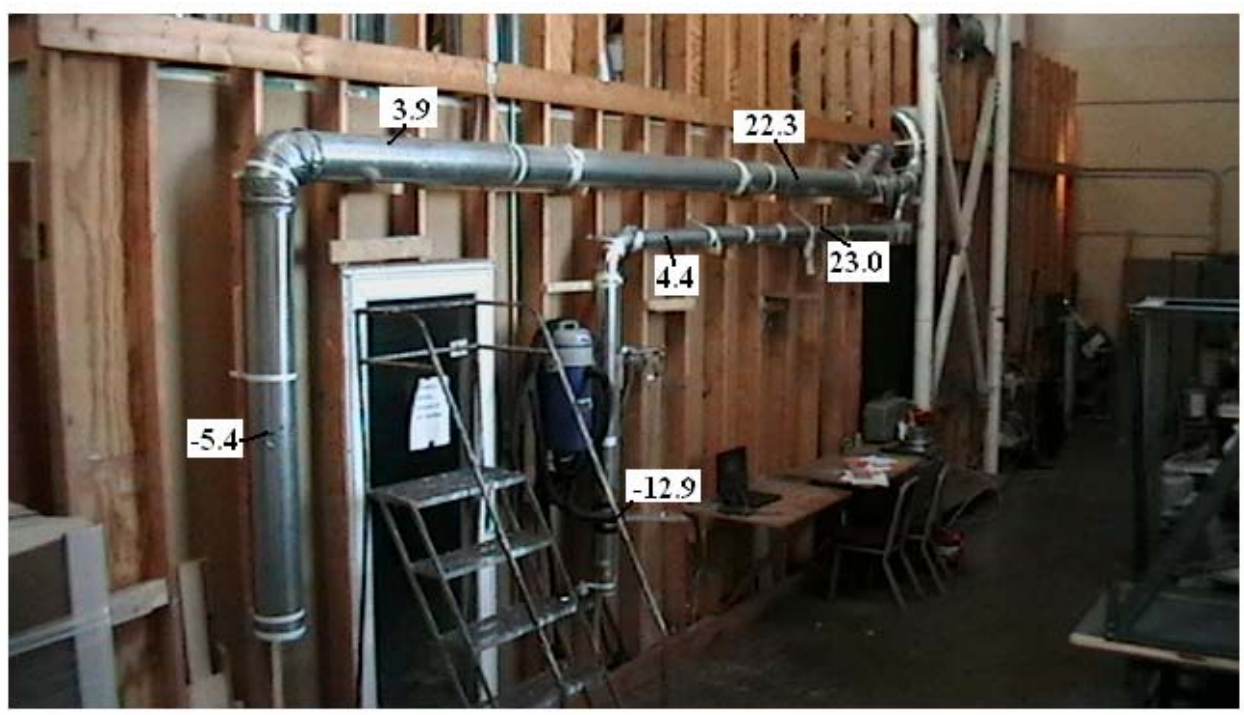

Figure 2: Experimental Duct System 
Table 2: Locations and Distances of Traverse Measurement Sites

\begin{tabular}{|c|c|c|}
\hline Diameter (D) & $\begin{array}{c}\text { Distance From } \\
\text { Elbow, in. (L) }\end{array}$ & $\begin{array}{c}\text { Distance From Elbow / Duct } \\
\text { Diameter } \\
\text { (L/D) }\end{array}$ \\
\hline 3.875 & -50 & -12.9 \\
\hline 3.875 & 17 & 4.4 \\
\hline 3.875 & 89 & 23 \\
\hline 6.875 & -37 & -5.4 \\
\hline 6.875 & 27 & 3.9 \\
\hline 6.875 & 153 & 22.3 \\
\hline
\end{tabular}

Directly upstream of the junction fitting in each branch is a sliding-gate damper (see Figure 3 ) used to control each branch flow separately. When measuring the air flow in the 3.875inch duct, the 6.875-inch gate damper was closed. Likewise, when measuring the air flow in the 6.875-inch duct, the 3.875-inch gate damper was closed. The slide-gate dampers were also used to adjust the air flow velocity to the desired 4500 FPM in each duct. This was done by adjusting the fan speed to a level such that each duct's velocity exceeded 4500 FPM while the other damper was closed. The damper for the tested duct was then closed slightly until the average velocity was 4500 FPM. Before each round of pressure measurements, the centerline velocity was measured at the most ideal flow locations, using the Airflow ${ }^{\mathrm{TM}}$ PVM100 on its Velocity Measurement setting, in order to assure that airflow velocity was the same each time measurements were conducted. The desired velocity, $4500 \mathrm{FPM}$, is equal to the measured centerline velocity (5000 FPM) multiplied by the pipe factor, 0.9 .

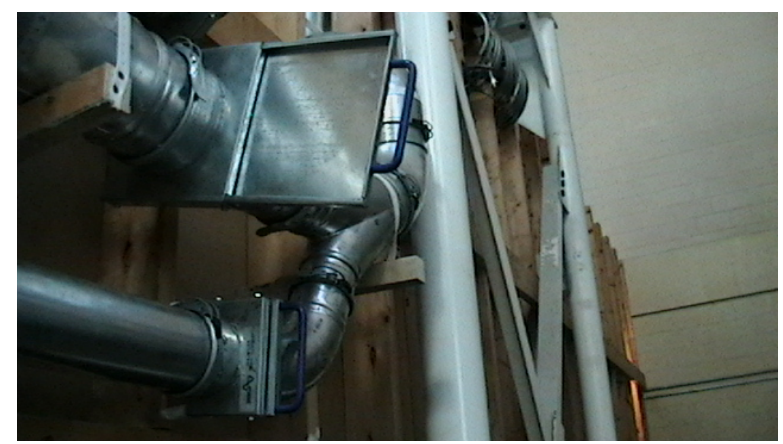

Figure 3: Control Dampers

A junction fitting, located just downstream from the slide-gate dampers was used to connect the two duct branches. Continuing downstream, a 5.875-inch duct was used to connect the experimental duct system to a centrifugal fan (Aerovent ${ }^{\mathrm{TM}}$ model 270 
ARR.4Cl.L) used to provide the airflow necessary for this experiment. The fan frequency $(\mathrm{Hz})$ is controlled using a digital variable frequency drive (Teco ${ }^{\mathrm{TM}}$ model N3-207-C)

The measuring station, the section of ducts in which all measurements were performed, was braced and fixed to the wall of the wind tunnel in order to eliminate any flow changes between measurements that could occur due to any accidental movement of the ducts. Also, in order to eliminate any chance of leaks in the system upstream of the junction, all the connections were sealed with silicone sealant and duct tape.

A platform ladder was used so that subjects could safely reach elevated locations. A 10 foot data cable was used so that the laptop computer could remain stationary during measurements, decreasing the likelihood of it falling and becoming damaged. Subjects inserted the Pitot tubes to the desired depths at each location while the investigator operated the software on the computer.

\subsection{Measurement Devices}

The following devices were used to conduct measurements relevant to the study. They are discussed in greater detail in the sub-sections that follow this heading.

- Pitot tubes

- Pitot tube holding device

- Digital manometer

- Psychrometer with wet bulb and dry bulb thermometers

- Barometer

- Personal computer with ventilation measurement software

\subsubsection{Hand Held Pitot Tube}

Two standard-head, 1/8 inch-diameter Dwyer ${ }^{\circledR}$ stainless steel Pitot tubes, compliant to ANSI/ASHRAE 41.2-1987 standards, (ASHRAE, 1993) were used to obtain measurements for the hand-held Pitot measurement portion of this study (see Figure 2). The smaller Pitot tube, used to traverse the 3.875-inch duct, was $6 \frac{3 / 4}{4}$ inches in length from the total pressure port to the elbow and $31 / 8$ inches in length from the elbow to the inlet probe and 2 inches in length from the elbow to the SP probe. The larger Pitot tube, used to traverse the 6.875inch duct, was 13 inches in length from the total pressure port to the elbow and $31 / 8$ inches in length from the elbow to the inlet probe and 2 inches in length from the elbow to the SP probe.

Since it is quite difficult to hold a Pitot tube perfectly perpendicular while achieving the proper insertion points, a method of marking the Pitot tubes, found in Industrial Ventilation (ACGIH, 2004), was utilized to simplify the task. The longer probe was marked with the insertion depths for a 6.85 inch duct and the smaller probe was marked with the insertion depths for a 3.85 inch duct (see Table 1). The insertion depths were marked using a fine-tip permanent marker and then etched with a small file. Finally, the etchings were re-inked with three colors to make the marks easier to see. 


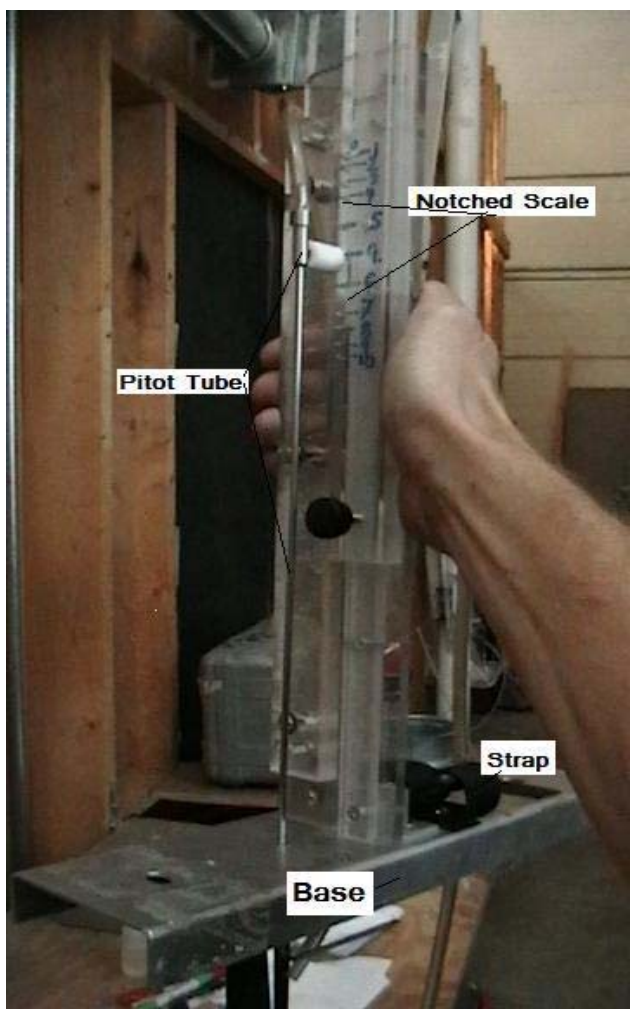

Figure 4: Pitot Tube Holding Device

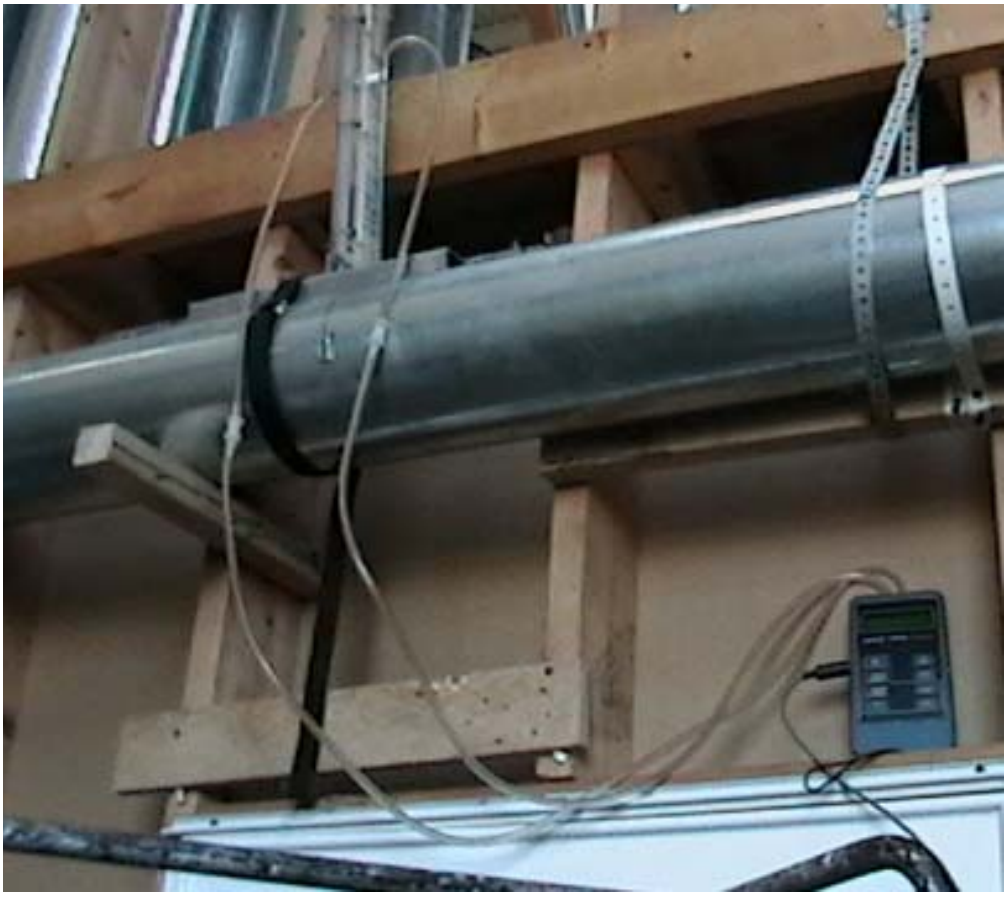

Figure 5: Traverse Device Measurement 


\subsubsection{Device Held Pitot Tube}

Guffey (1999) describes a device that holds the Pitot tube in line with the duct at the correct insertion depth. This device holds the Pitot tube in its proper position, eliminating yaw and pitch. A notched scale is used to achieve proper insertion points within a few hundredths of an inch. This scale can be replaced with a different sized scale, depending on the size of the duct to be traversed. In this case, two scales were made with notches appropriate for a 3.85 inch duct and another for a 6.85 inch duct. Since the device is fixed in place on the duct using Velcro straps and duct tape, there are no issues with unintentional movement of the probe tip.

\subsubsection{Digital Manometer}

Digital manometers are electronic devices that use piezo-resistance or strain gauges to sense pressure changes. One advantage that digital manometers have over other ventilation measuring devices is that they do not need to be held upright. These devices have quick response capabilities and can be highly accurate as well. Also, many digital manometers have data logging capabilities and can communicate with computers using appropriate software.

The digital manometer used in this research study was the Airflow ${ }^{\mathrm{TM}}$ PVM100 Micromanometer. The pressure resolution of this manometer is $1 \mathrm{~Pa}(0.001$ in. w.g.). This manometer was calibrated by measuring known pressures from 0.0 to 4.0 inches w.g. that were created by a hand pump (Meriam Instrument) and measured in parallel with a 1425 Hook Gauge (Dwyer Instruments).

The manometer was connected to the Pitot tubes by $0.25^{\prime \prime}$ plastic tubing at each leg of a Pitot tube and to each port of the manometer. Male and matching female plastic couplers were connected to the end of each plastic tube, allowing quick connection and removal without creating leaks from stretching the plastic tubing by attaching it and removing it from the Pitot tubes and manometer.

\subsubsection{Environmental Measurements}

Air density affects the flow of air, and must be calculated each time an air flow measurement is made. A Psychro-Dyne ${ }^{\mathrm{TM}}$ psychrometer (Cole-Parmer) was employed to measure wet and dry bulb temperatures, allowing the determination of relative humidity, which is necessary for determining the air density. The thermometers on the PyschroDyne $^{\mathrm{TM}}$ psychrometer were calibrated with an Ertco $^{\mathrm{TM}}$ model 8859 nitrogen-filled calibration thermometer.

A Princo ${ }^{\mathrm{TM}}$ barometer, model 453, located on the opposite wall of the wind tunnel room, was used to measure the barometric pressure.

\subsubsection{Data Acquisition Software}

HvMeasurement is a custom-made program written by Dr. Steven Guffey (1403 Far Meadows, Morgantown, WV 26508). It performs the following functions to aid in taking static pressure and Pitot traverse readings in the field: 
- Acquires measurement values from a digital manometer connected to the serial port of the computer (see Figure 8).

- Displays velocity contours for one or both perpendicular traverses

- Checks for indications of measurement errors.

- Accepts keyboard inputs for measured temperature, humidity, altitude, and barometric pressure

- Computes observed average velocities, airflows, densities, and system resistance values.

As a traverse is completed, the software shows the developing velocity profile of velocity pressures on screen (see Figure 7). By viewing the velocity profiles, the user can determine if any gross mistakes were made and whether or not any measurements should be re-done.

The HvMeasurement program also computes the density factor using Equation 2 and the individual and mean velocities using Equations 1 and 3. In doing so, it first computes the humidity mass ratio $(\omega)$ using a software algorithm.

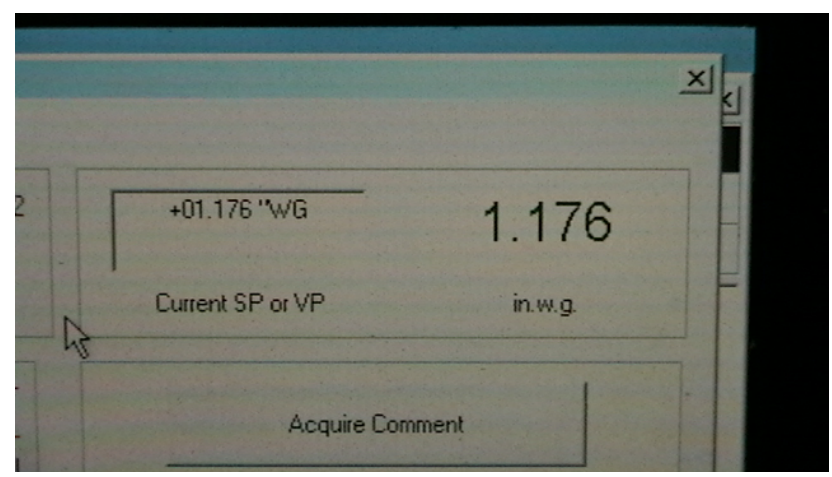

Figure 6: Manometer Display on Computer Screen

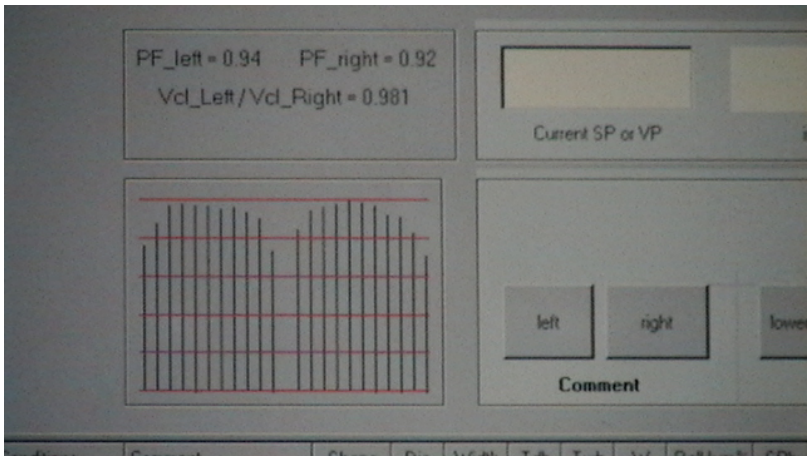

Figure 7: Velocity Profile 


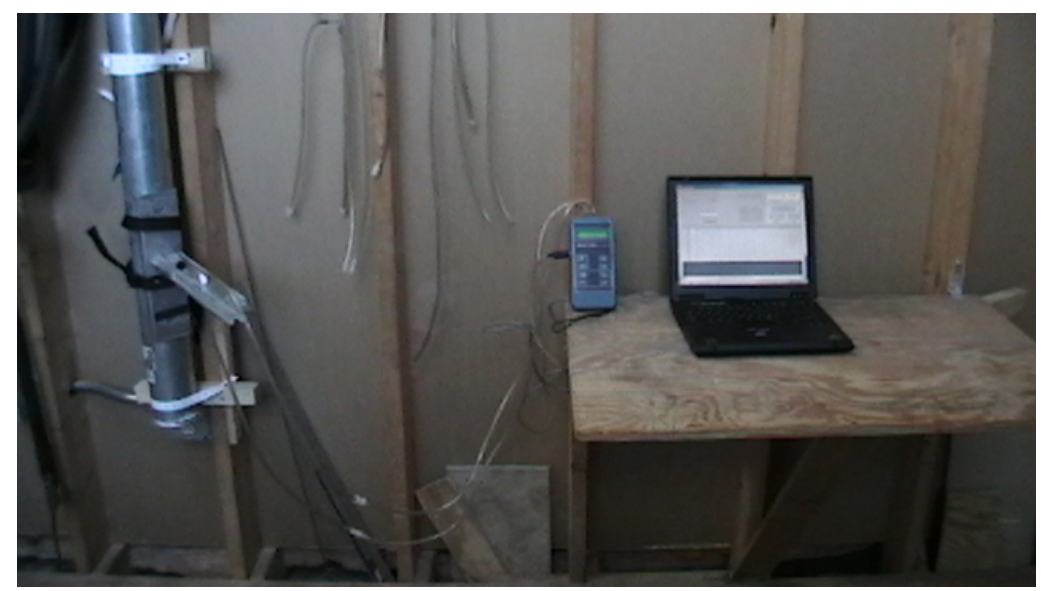

Figure 8: Pitot Tube, Manometer, and Computer Connected

\subsection{Human Test Subjects}

Nine test subjects with various levels of prior measuring experience using Pitot tubes were used to obtain the data for the hand-held portion of data collection. Each test subject completed two complete rounds of measurements, each time on a different day. A round of measurements included both traverses at each of the 3 locations on each duct. 


\subsection{Methods}

\subsection{Apparatus Set-up}

Setting up the work station required attaching the Pitot tube to the manometer, using plastic tubing, and the manometer to the serial port of a computer (see Figure 8). The manometer was turned on 20 minutes prior to measurements to allow for adequate warm-up. Also, after the fan was turned on to the desired fan frequency, a waiting period of at least 2 minutes was observed. Before each set of measurements are made, wet-bulb, dry-bulb, and barometric pressure is recorded. The same also was recorded after each trial, so that an average of initial and final wet-bulb, dry-bulb, and barometric pressure can be calculated and used. The hand held Pitot tube is connected to the set-up in a similar fashion.

Using two perpendicular ten-point traverses, velocity pressure was manually measured in each of the three locations on each of the ducts (see Figure 2), by all subjects. The same traverses were done by the investigator using the traverse device. Static pressure was also taken at each measurement location. Nine subjects performed two complete replications of the hand-held measurements. Five replications were performed using the device-held pitot measurements at all sampling locations. All measurements were taken over several days from August 14, 2007 to September 21, 2007. Hand-held and traverse-device measurements were taken on different days. The order of locations tested for each was done in a randomized order.

\subsection{Conducting Device-Held Pitot Traverse Measurements}

The following procedures were used to conduct the traverse device measurements, including steps for setting up the instrumentation, measuring, and recording the data. Figure 11 shows the Traverse Device in use at $L / D=3.9$. Instrumentation set up consisted of the following procedure:

\section{Turn on AIRFLOW PVM 100 Manometer}

2. Turn on computer and open HvMeasurement software.

3. Connect Manometer to serial connector on laptop.

4. On the HvMeasurement program, perform the following operations:

a. Select 'Sequential ID's'

b. Select 'AIRFLOW'M PVM 100'

c. Enter altitude of 960 feet, for the city of Morgantown, WV

d. Enter 'Start Acquisition'

5. Turn on fan to $33 \mathrm{~Hz}$ for the 4 -inch duct or $54.6 \mathrm{~Hz}$ for the 7 -inch duct. Wait at least 2 minutes after speed selection to conduct traverses.

6. After wetting the sock of the wet-bulb thermometer on the psychrometer, turn on the psychrometer fan. 
7. Measure and record initial barometric pressure onto the task sheet next to the task list.

8. After the psychrometer fan has ran for at least 2 minutes, record initial wet bulb and dry bulb temperatures from psychrometer.

9. After the digital manometer has have been powered on for a 10 minute or longer warm-up period, begin measurement process.

The pressure measurement consisted of the following procedure:

1. Connect the male and female couplers on the ends of tubes together on the digital manometer and press the 'zero' button to zero it. Once digital reading shows ' \pm 0.000 ', then the digital manometer is zeroed.

2. Place the Pitot Traverse Device on the first traverse of the first measurement location and secure it in place with the Velcro straps and duct tape, if necessary, making certain that the appropriate scale is attached to the device.

3. Zero the notched Pitot tube scale, such that the Pitot tube is fully inserted when the scale indicates that it is.

4. Open and close appropriate slide gate dampers.

5. Connect the male and female couplers on the ends of tubes of the digital manometer to the couplers on the TP and SP ends of the Pitot tube.

6. With Pitot tube in the first traverse position on the first measurement location, begin measuring velocity pressure. On the HvMeasurement program, measure and record all 10 points, plus the center line, until values VP1-VP10 plus the VP for the center line are filled.

7. To record the End Static Pressure for this location, disconnect the 'Total Pressure' leg from Pitot tube and place the Pitot tube in the center line position. Measure and record the value on the same row of data as VP1-VP10.

8. With Pitot tube in the second traverse position on the first measurement location, begin measuring velocity pressure. On the HvMeasurement program, measure and record the 10 points of the other traverse diameter, plus the center line, until values VP11-VP20 plus the VP for the center line are filled. VP11-VP20 are on the same row of data as VP1-VP10 and the End Static Pressure for this location.

9. Reconnect the Total Pressure leg so that Velocity Pressure Measurements can be resumed.

10. Disconnect Pitot device from the first location and reconnect at the next location 11. Perform steps 1-10 for the next 5 locations. 
12. Measure and record final wet-bulb temperature, dry-bulb temperature, and barometric pressure onto the task sheet next to the initial temperatures and pressure on the task list. Calculate the average temperatures and pressure and enter the values into the software.

When measurements were made at one location, the duct access holes at the other locations were sealed off with duct tape to eliminate any potential Venturi effects, static pressure losses, flow losses, or any other losses.

\subsection{Conducting Hand-Held Pitot Traverse Measurements}

Each of the nine test subjects performed two replications of measurements on different days, each on different days. Prior experience with Pitot traverse measurements was not required for the subjects. Training was, however, given to those who had little or no experience with Pitot traverse measurement. Training consisted of showing each individual how to hold the Pitot tube perpendicular to the duct and how to use the colored etch marks to achieve the proper insertion depths.

The measurement procedure for each subject was the same as for the device-held measurements, except that the subjects held the Pitot tube by hand to perform each traverse (see Figure 9). Subjects stood on a platform ladder while the investigator operated the software, triggering the data acquisition at each point when the subject indicated readiness. The investigator made sure that no traverse points were missed. The investigator did not point out apparent errors or have the subject re-do erroneous measurements unless the subject was at the wrong insertion point. Figure 9 shows a hand-held traverse in progress at $L / D=3.9$. 


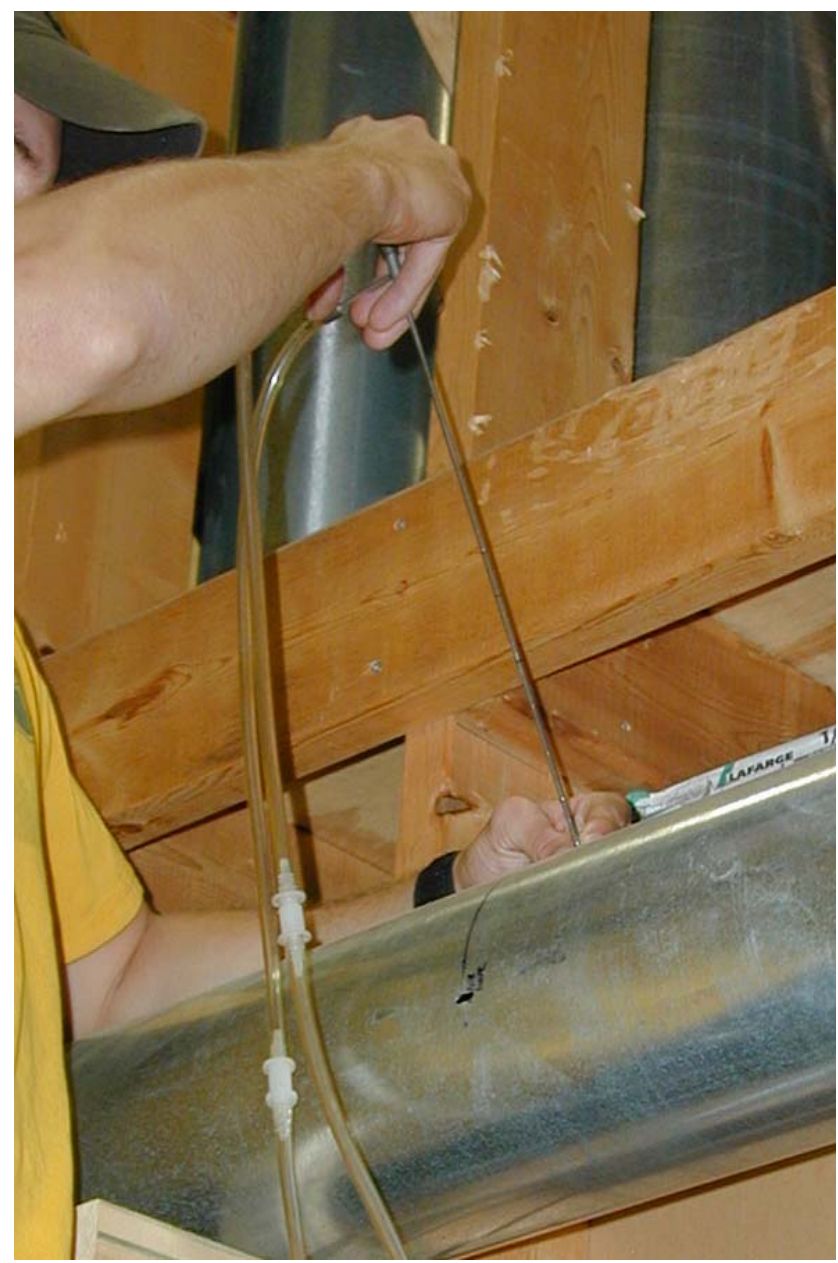

Figure 9: Hand Held Pitot Traverse

\subsection{Analyses of Results}

It is expected that the accuracy of the velocities calculated from traverse device pressure measurements will vary from locations where the flow is expected to be in-line with the flow (i.e., $\mathrm{L} / \mathrm{D}=30$ and 22.3) with locations much closer to the elbows ( $\mathrm{L} / \mathrm{D}=3.9$ and 4.4 ) or the duct entries $(\mathrm{L} / \mathrm{D}=-12.9$ and -5.4$)$. This is because of the unstable flow conditions at the non-optimal conditions.

In order to determine the effects of measurement location on the accuracy of Pitot traverse measurement; it is first necessary to create an ideal 'true' measurement in the ducts to provide a basis of comparison. Since there is no way to know the exact velocity through the duct, the next best thing is to use average of the traverse device velocity measurements at the most ideal locations as the presumed 'true' measurements, Vref. For this study, the best available location was at $\mathrm{L} / \mathrm{D}=23.0$ for the 3.85 inch duct and $\mathrm{L} / \mathrm{D}=22.3$ for the 6.85 inch duct. These values are referred to as the Reference values.

The \%DeviationFromReference was calculated for the average values for the device at other locations from: 
$\%$ DeviationFromReference $=\frac{\bar{V}_{D}-\bar{V}_{\text {Ref }}}{\bar{V}_{R e f}}$

It was computed for the average of both replications for the hand-held measurement by each human subject at all locations from:

$\%$ DeviationFromReference $=\frac{\bar{V}_{H}-\bar{V}_{\text {Ref }}}{\bar{V}_{R e f}}$

Assuming that the values for the traverse device represent the most accurate readings possible even at less than ideal locations, the results for the hand-held measurements were compared to the mean values for the traverse device for the same locations using:

$\%$ DeviationFromDevice $=\frac{\bar{V}_{H}-\bar{V}_{D}}{\bar{V}_{D}}$

Similar values were compared for static pressure readings taken by subjects $\left(\mathrm{SP}_{\mathrm{H}}\right)$ and using the traverse device at the same location $\left(\mathrm{SP}_{\mathrm{D}}\right)$. In this case the values of static pressure would vary with location, so the values from far downstream cannot be compared to values taken at other locations:

$\%$ DeviationFromDevice $=\frac{\overline{S P}_{H}-\overline{S P}_{D}}{\overline{S P}_{D}}$ 


\subsection{Results}

After the collection of all device and hand-held data, the results were exported from HvMeasurement to MS Excel ${ }^{\mathrm{TM}}$ spreadsheet to be analyzed. Using a combination of operations from both Data Desk ${ }^{\mathrm{TM}} 6.0$ (DataDescription, Inc., Ithaca, NY) statistical software and Excel ${ }^{\mathrm{TM}}$, the results were calculated from the values computed by HvMeasurement.

\subsection{Measured Velocity Profiles in Ducts}

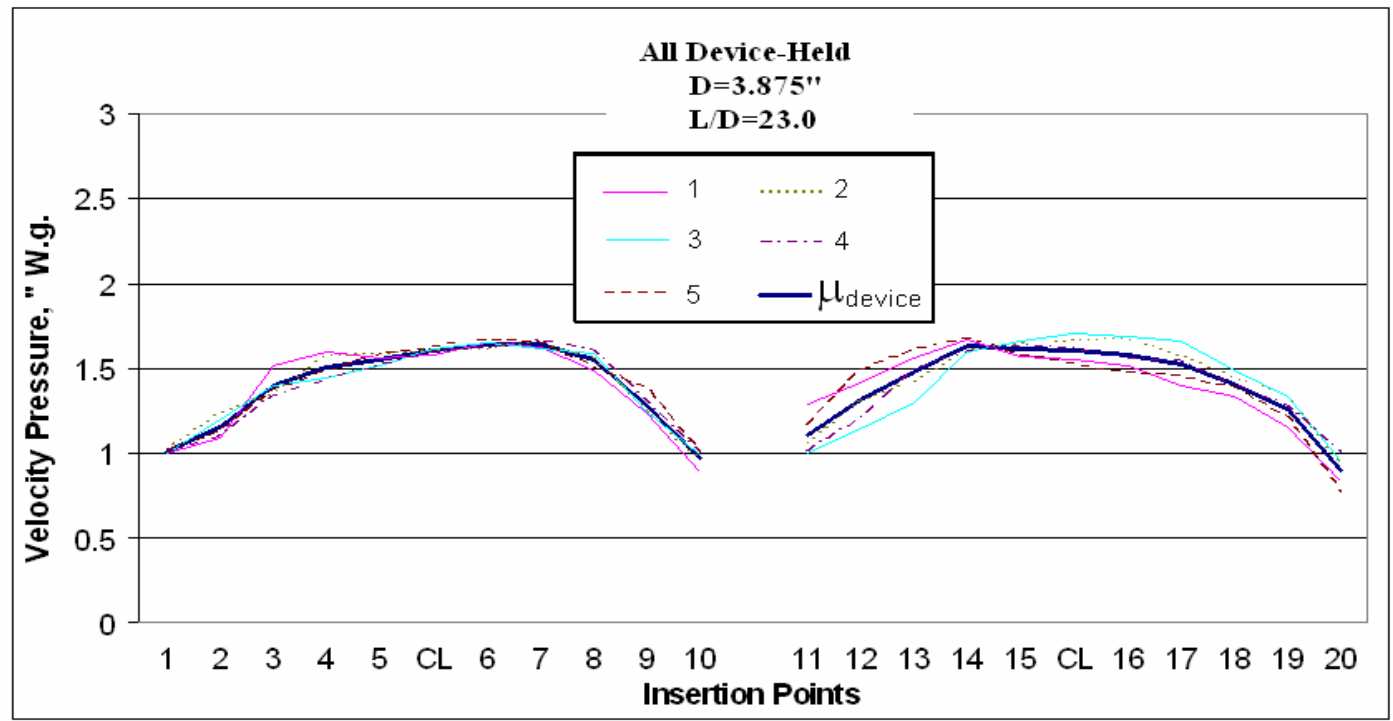

Figure 10a: VP Profiles of All Traverse Device: $L / D=23.0$

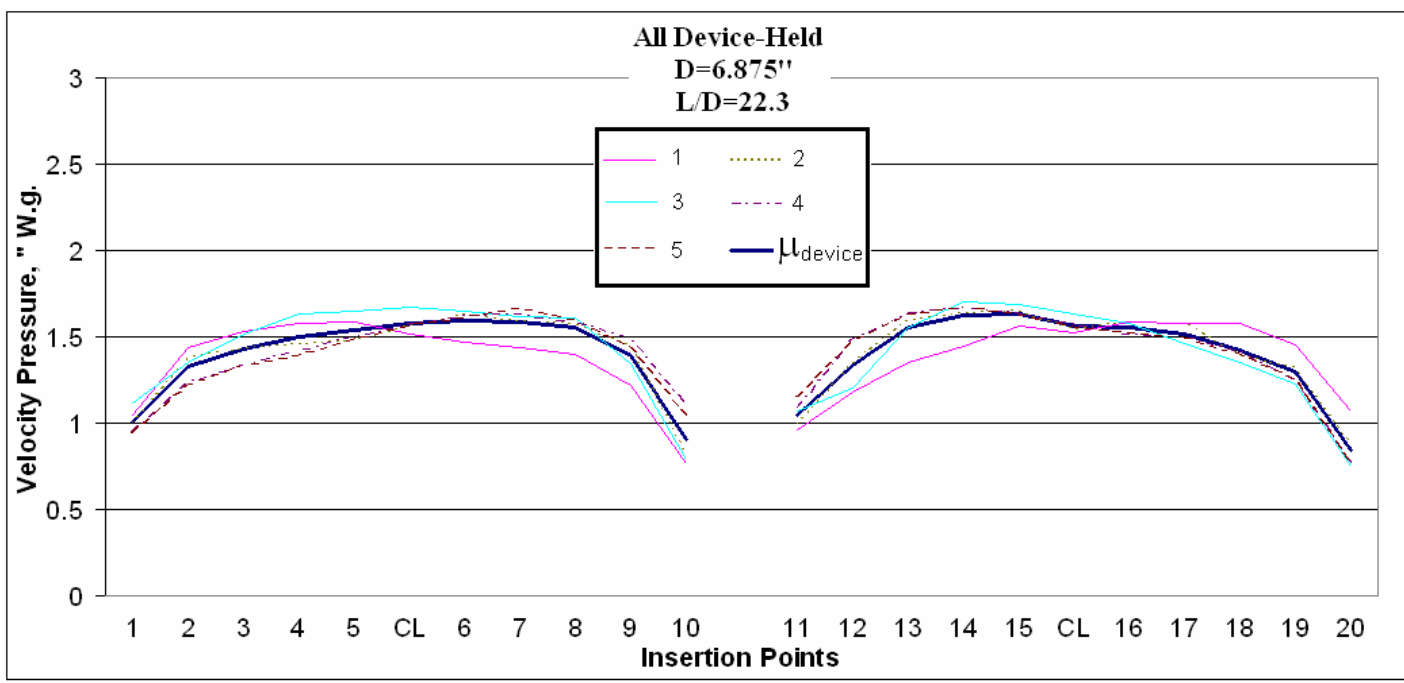

Figure 10b: VP Profiles of All Traverse Device: $L / D=22.3$ 
The velocity pressures measured from the traverse device were plotted to show profiles of each measurement position (see Figures 10a-10b). The averages of the device velocity pressures were calculated and are labeled by the bold blue line. As shown on Figures 10.110.2 , the velocity pressure (VP) contour was highly repeatable for $\mathrm{V}_{\text {Ref. }}$. The profiles were skewed moderately to one side, perhaps suggesting that $L / D=23$ is not sufficient distance from an elbow to form perfect symmetry.

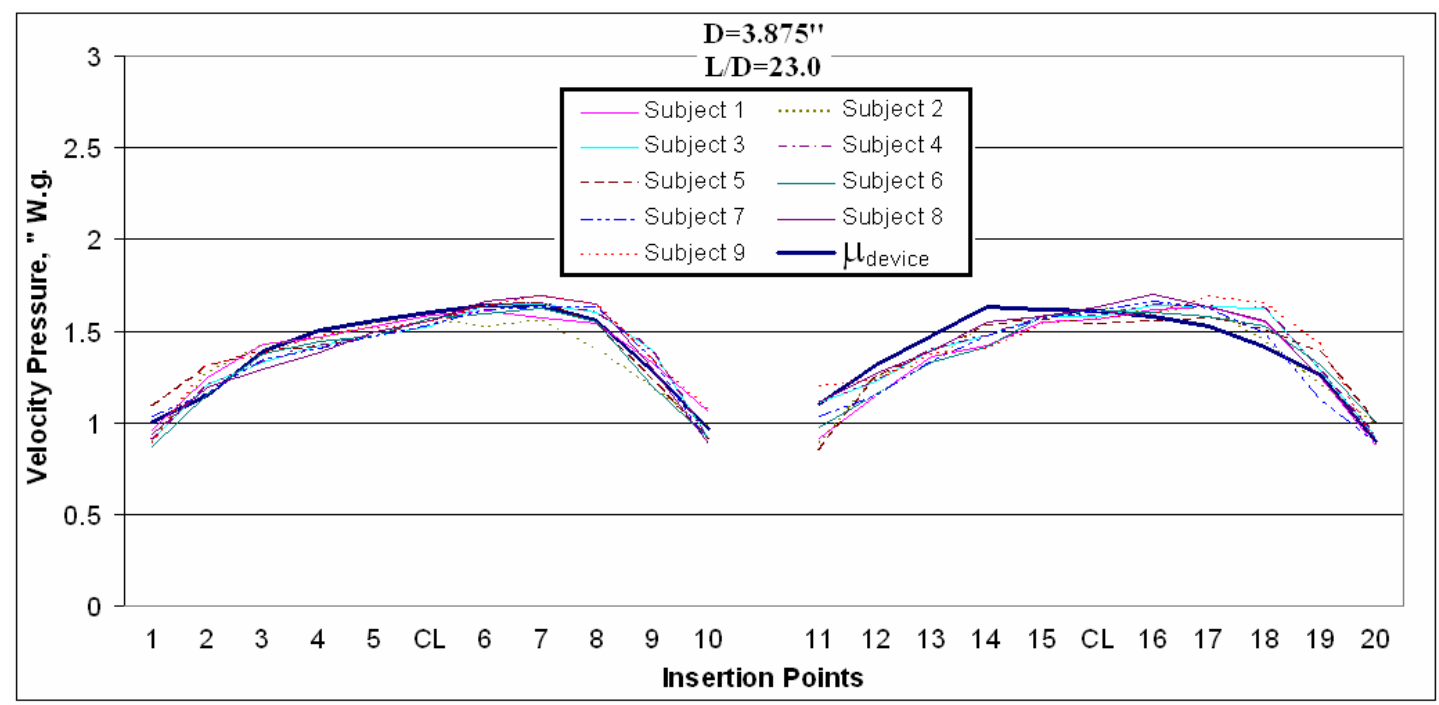

Figure 10c: VP Profiles of Hand-Held Means: L/D = 23

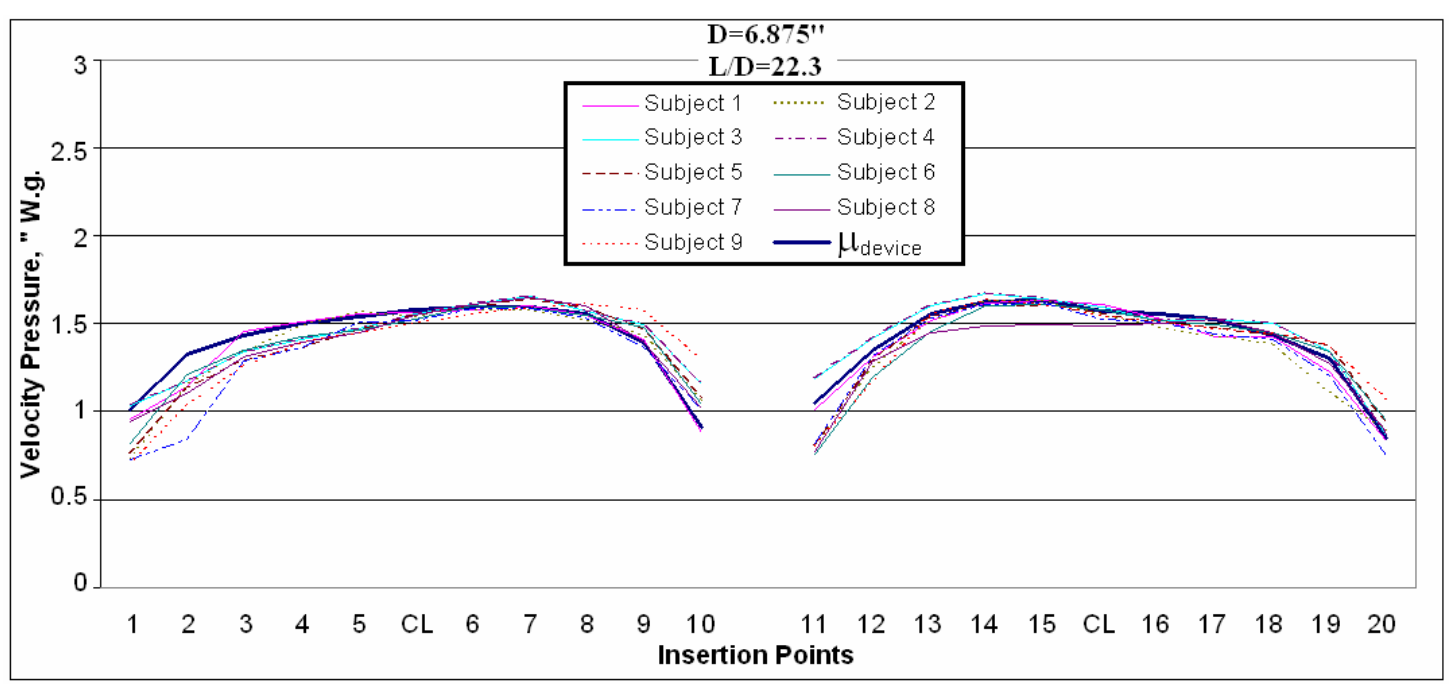

Figure 10d: VP Profiles of Hand-Held Means: L/D = 22.3 


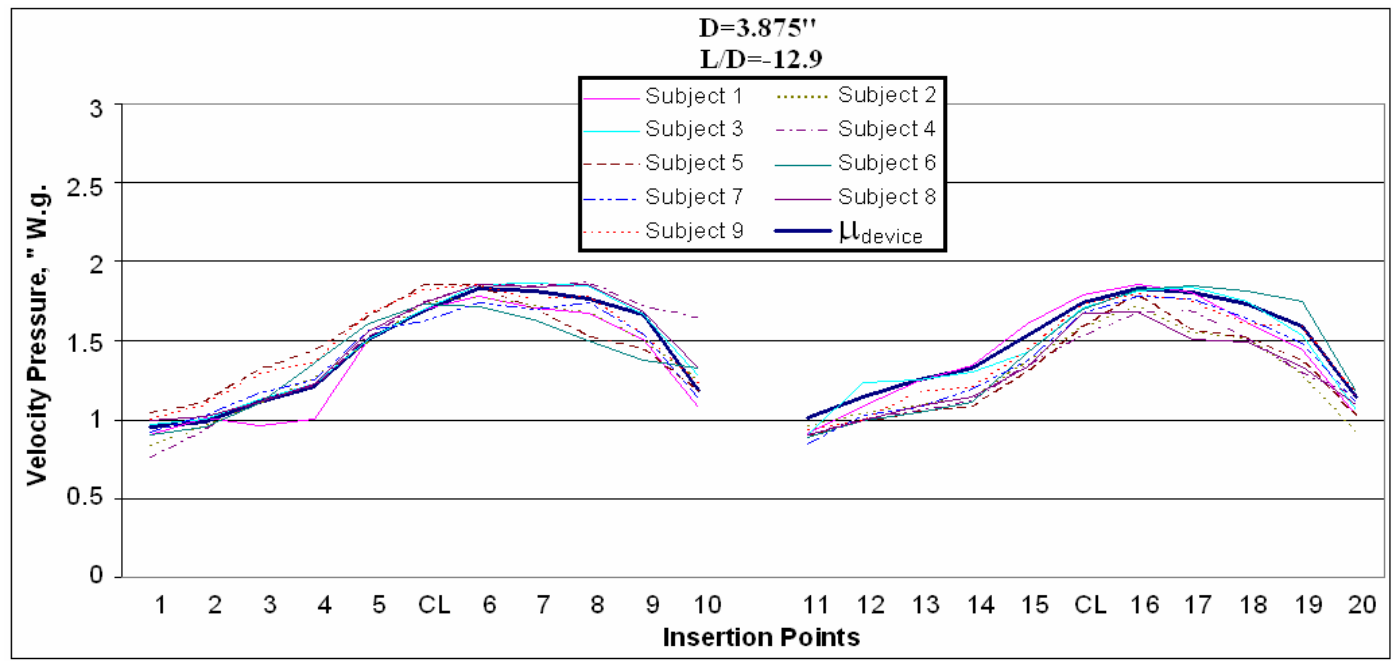

Figure 10e: VP Profiles of Hand-Held Means: $L / D=-12.9$

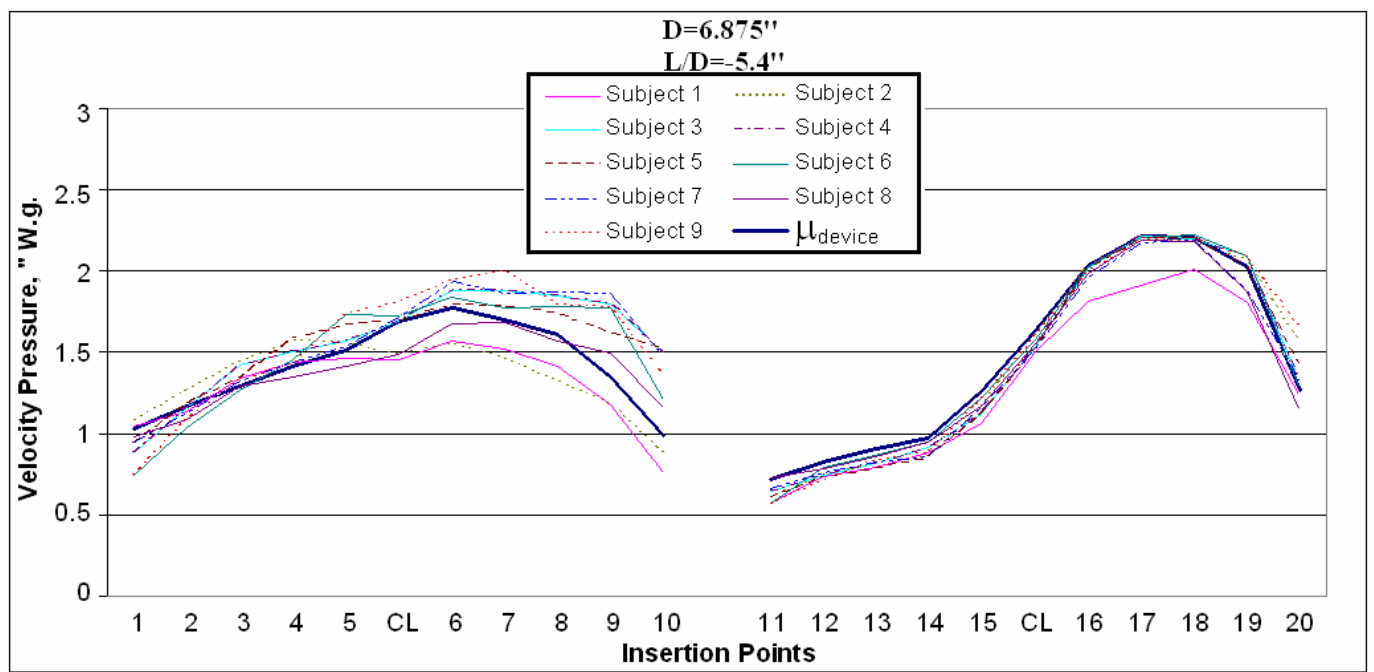

Figure 10f: VP Profiles of Hand-Held Means: $L / D=-5.4$ 


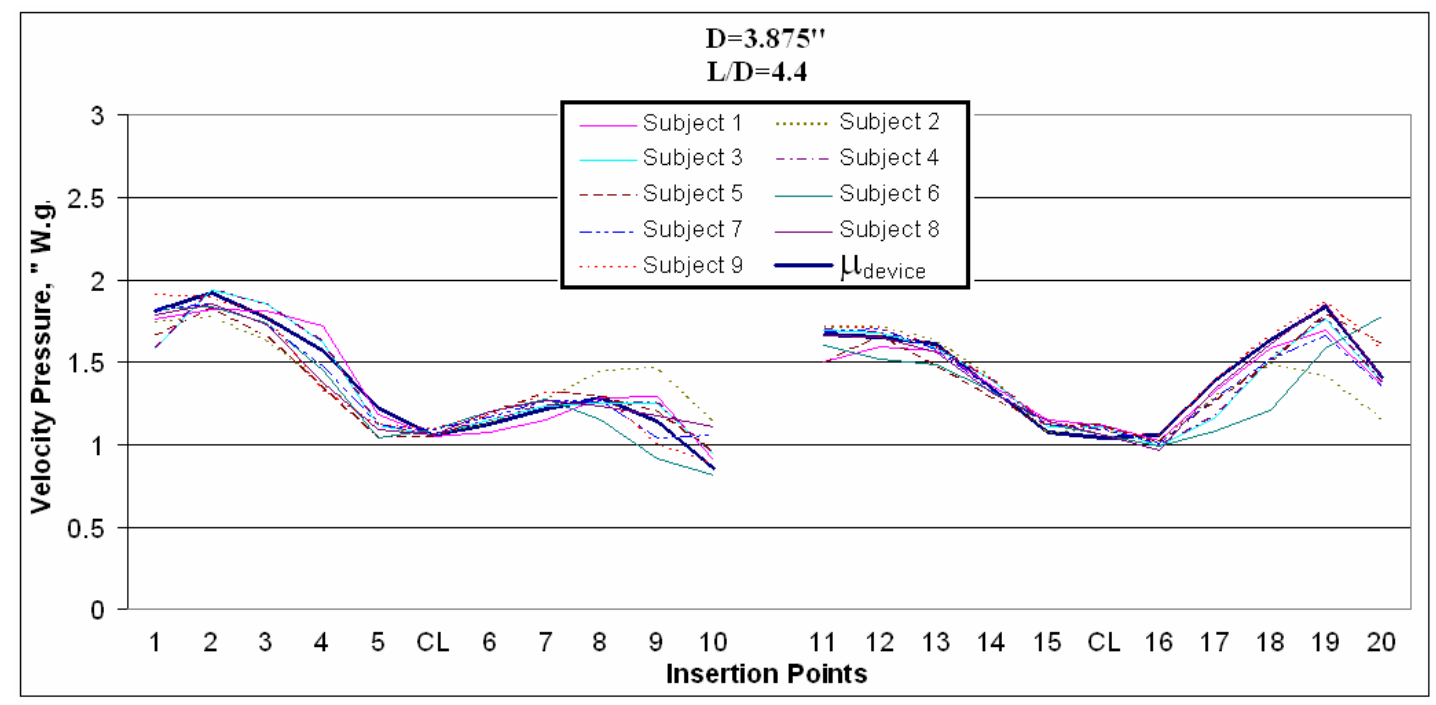

Figure 10g: VP Profiles of Hand-Held Means: L/D = 4.4

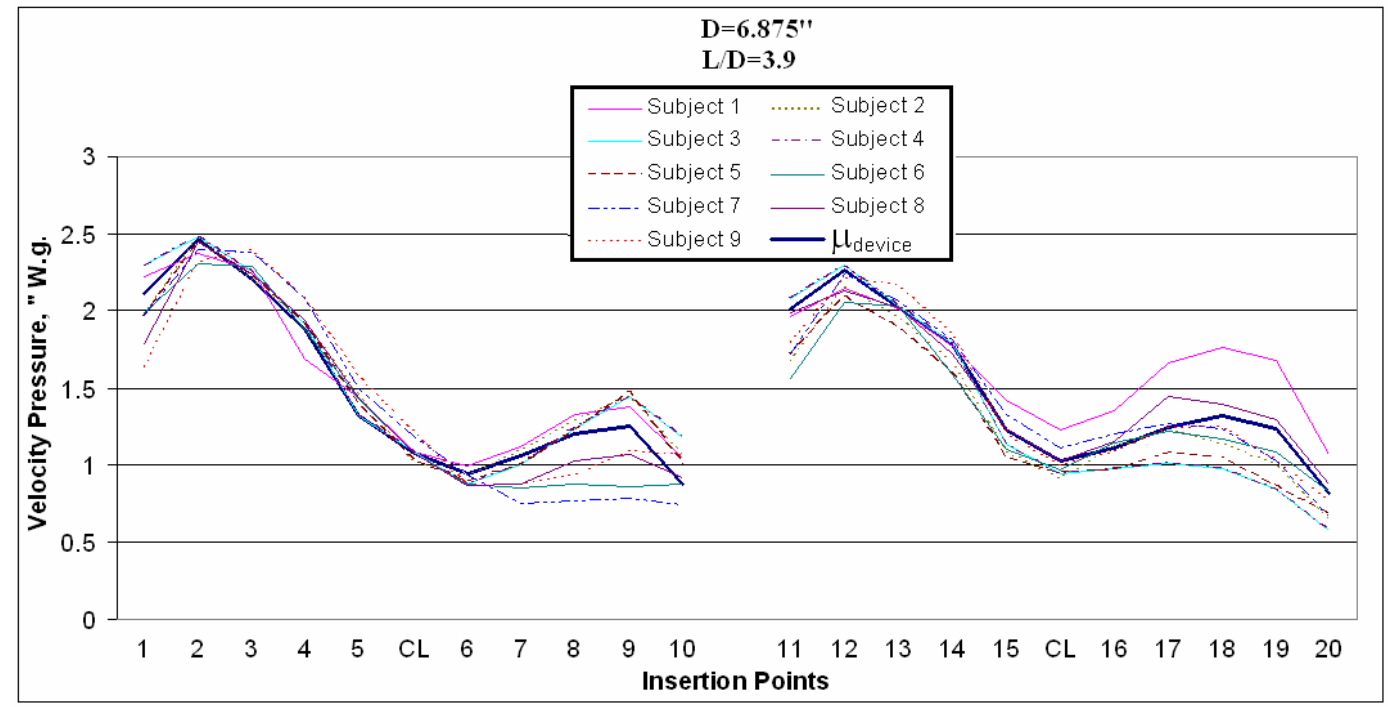

Figure 10h: VP Profiles of Hand-Held Means: L/D = 3.9

The velocity pressures measured by hand from the test subjects were also plotted (see Figures 10c-10h). Again, the averages of the device velocity pressures, labeled by the bold blue line, are included in each plot. For the human subjects doing traverses at the most downstream locations (see Figures 10c and 10d), the results were very similar from one subject to another. They deviated from the traverse device results slightly differently, depending on the duct diameter and whether it was the first or second traverse diameter. 
At $\mathrm{L} / \mathrm{D}=-12.9$, which is 4 diameters distance downstream of the plain duct opening, the human and device contours are very similar and are more skewed than the far downstream values (see Figure 10e). This is somewhat surprising since the plain duct entry is itself highly symmetrical.

As shown in Figure 10f, for traverse locations not far upstream of the elbows (L/D = -5.4) and 4D downstream from the plain duct openings, the human and device contours are very similar. The first traverse diameter, which is perpendicular to the plane of the elbow, is nearly symmetrical. The second traverse diameter, which is parallel to the plane of the elbow, is skewed strongly to one side.

As shown in Figures $10 \mathrm{~g}$ and $10 \mathrm{~h}$, at $\mathrm{L} / \mathrm{D}=4.4$ and 3.9, the VP contours are not at all symmetrical in either traverse diameter. However, the hand-held and device contours are very similar.

\subsection{Errors in Velocity}

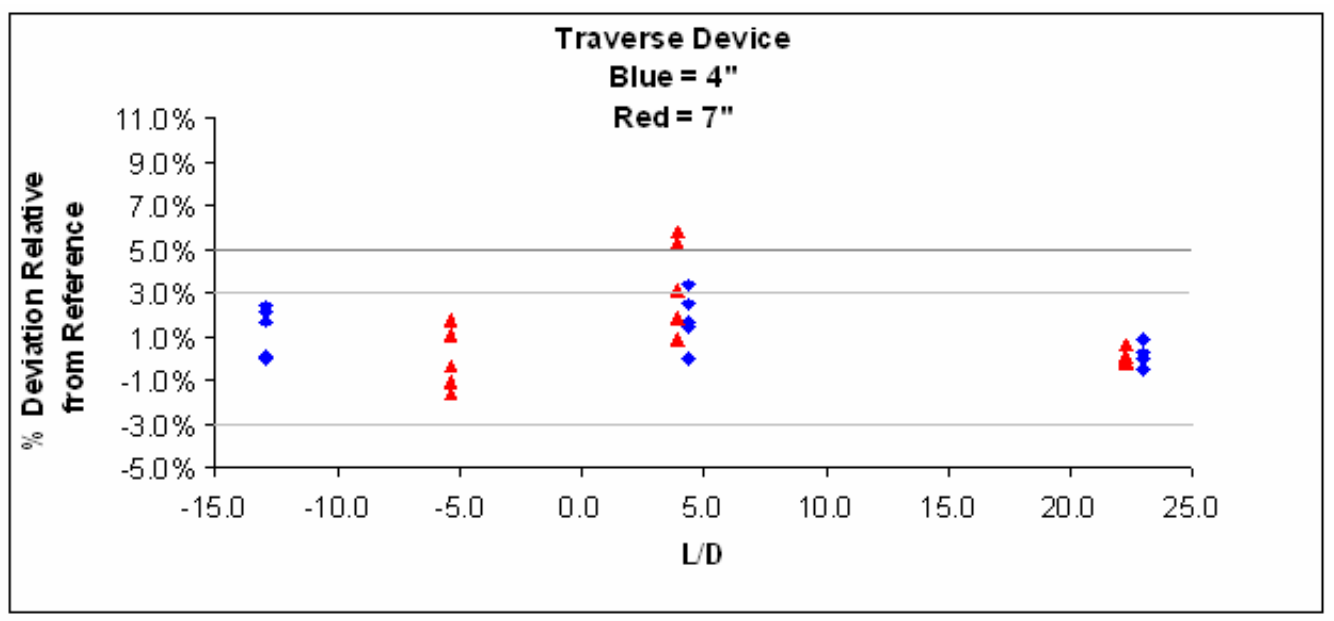

Figure 11: Device Relative Deviation from Reference - Velocity

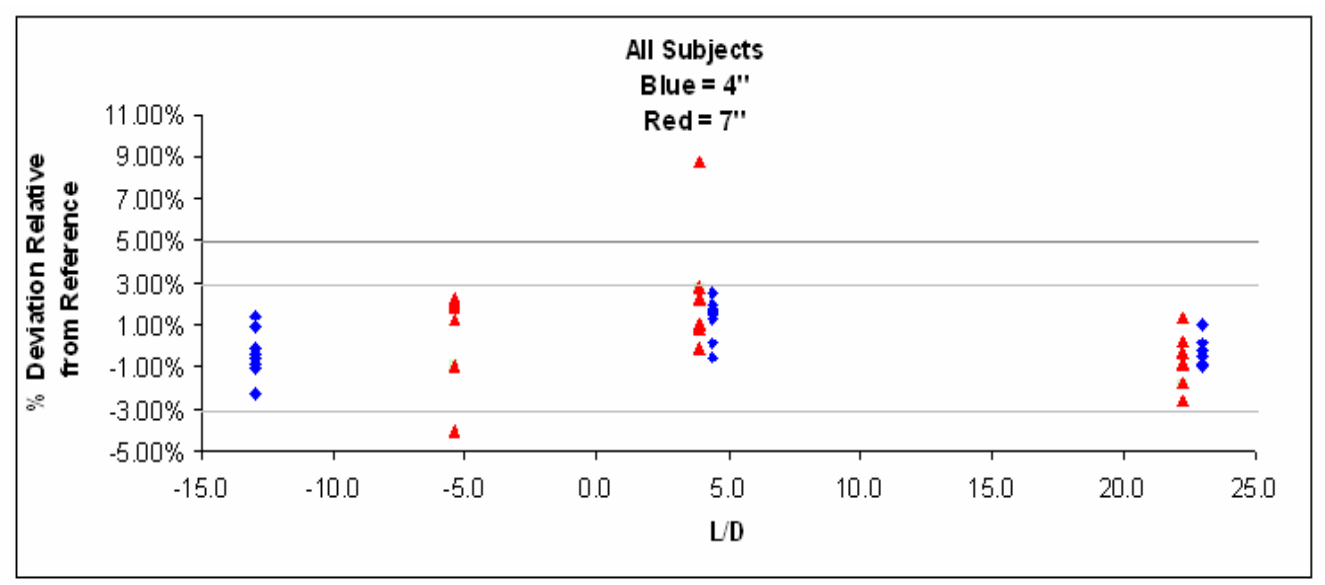

Figure 12: Hand-Held Relative Deviation from Reference-Velocity 


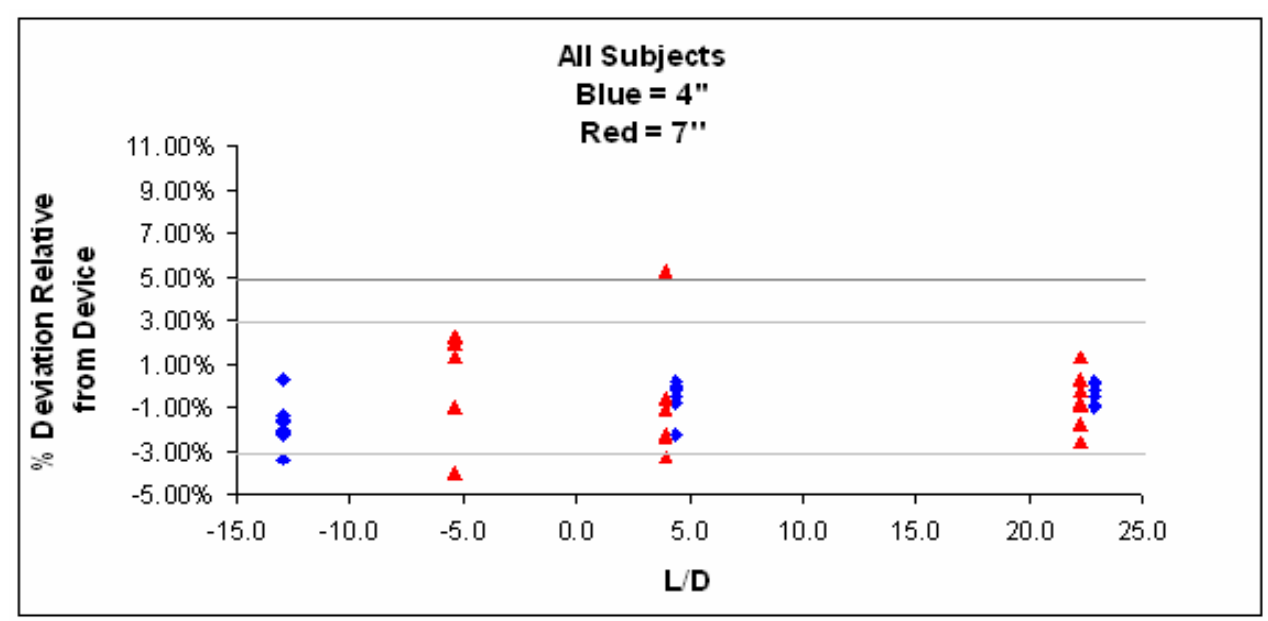

Figure 13: Hand-Held Relative Deviation from Device-Velocity

Table 3: Results of Mean Traverse Device and All Hand-Held-Velocity

\begin{tabular}{|c|c|c|c|c|c|c|c|c|}
\hline & & & & & & & $\begin{array}{c}\text { Hand \% } \\
\text { Deviation } \\
\text { From } \\
\text { Device }\end{array}$ & $\begin{array}{c}\text { Hand \% } \\
\text { Deviation } \\
\text { From } \\
\text { Reference }\end{array}$ \\
\hline$\underline{\mathrm{V}}_{\text {Device }}$ & 3.875 & 23 & 4783 & 4783 & 28.2 & $0.59 \%$ & N/A & N/A \\
\hline$\underline{\mathrm{V}}_{\text {Hand }}$ & 3.875 & 23 & 4773 & 4783 & 31.9 & $0.70 \%$ & $-0.20 \%$ & $-0.20 \%$ \\
\hline$\underline{\mathrm{V}}_{\text {Device }}$ & 6.875 & 22.3 & 4804 & 4804 & 16.4 & $0.34 \%$ & $\mathrm{~N} / \mathrm{A}$ & $\mathrm{N} / \mathrm{A}$ \\
\hline$\underline{\mathrm{V}}_{\text {Hand }}$ & 6.875 & 22.3 & 4763 & 4804 & 57.2 & $1.20 \%$ & $-0.80 \%$ & $-0.80 \%$ \\
\hline$\underline{\mathrm{V}}_{\text {Device }}$ & 3.875 & 4.4 & 4868 & 4783 & 61.6 & $1.27 \%$ & $\mathrm{~N} / \mathrm{A}$ & $1.80 \%$ \\
\hline$\underline{\mathrm{V}}_{\text {Hand }}$ & 3.875 & 4.4 & 4851 & 4783 & 40.8 & $0.80 \%$ & $-0.40 \%$ & $1.40 \%$ \\
\hline$\underline{\mathrm{V}}_{\text {Device }}$ & 6.875 & 3.9 & 4966 & 4804 & 101.2 & $2.04 \%$ & $\mathrm{~N} / \mathrm{A}$ & $3.40 \%$ \\
\hline$\underline{\mathrm{V}}_{\text {Hand }}$ & 6.875 & 3.9 & 4919 & 4804 & 123.9 & $2.50 \%$ & $-0.90 \%$ & $2.40 \%$ \\
\hline$\underline{\mathrm{V}}_{\text {Device }}$ & 3.875 & -12.9 & 4843 & 4783 & 53.4 & $1.10 \%$ & $\mathrm{~N} / \mathrm{A}$ & $1.20 \%$ \\
\hline$\underline{\mathrm{V}}_{\text {Hand }}$ & 3.875 & -12.9 & 4766 & 4783 & 56.1 & $1.20 \%$ & $-1.60 \%$ & $-0.40 \%$ \\
\hline$\underline{\mathrm{V}}_{\text {Device }}$ & 6.875 & -5.4 & 4802 & 4804 & 69.1 & $1.40 \%$ & $\mathrm{~N} / \mathrm{A}$ & $0.00 \%$ \\
\hline$\underline{\mathrm{V}}_{\text {Hand }}$ & 6.875 & -5.4 & 4834 & 4804 & 105.6 & $2.20 \%$ & $0.70 \%$ & $0.60 \%$ \\
\hline
\end{tabular}

As shown on Figure 11 and Table 3, the location relative to the elbow and plain duct entry affected even the traverse device results, as expected (Guffey and Booth, 1999). The coefficient of variation (C.V.) for the most downstream locations ( $\mathrm{L} / \mathrm{D}=23.0$ and 22.3) was $0.59 \%$ and $0.34 \%$, respectively. At $\mathrm{L} / \mathrm{D}=-12.9$ and -5.4 , it was $1.1 \%$ and 1.4 . At $\mathrm{L} / \mathrm{D}$ $=4.4$ and 3.9 , it was $1.3 \%$ and $2.0 \%$. The deviations from $\mathrm{V}_{\text {Ref }}$ were due to flows not being parallel to the duct, introducing yaw and pitch errors for the Pitot tube.

As shown on Figure 12 and Table 3, the location relative to the elbow and plain duct entry also affected human subject results by roughly the same amount as the traverse device results. The coefficient of variation (C.V.) for $\mathrm{L} / \mathrm{D}=23.0$ and 22.3 was $0.7 \%$ and $1.2 \%$. At 
$\mathrm{L} / \mathrm{D}=-12.9$ and -5.4 it was $1.2 \%$ it was $1.4 \%$. At $\mathrm{L} / \mathrm{D}=4.4$ and 3.9 it was $0.8 \%$ and 2.5 . Again, the deviations from $\mathrm{V}_{\mathrm{Ref}}$ are due to flows not being parallel to the duct, introducing yaw and pitch errors for the Pitot tube. The coefficients of variation of the human subject results are not substantially different than the coefficients of variation of the traverse device results.

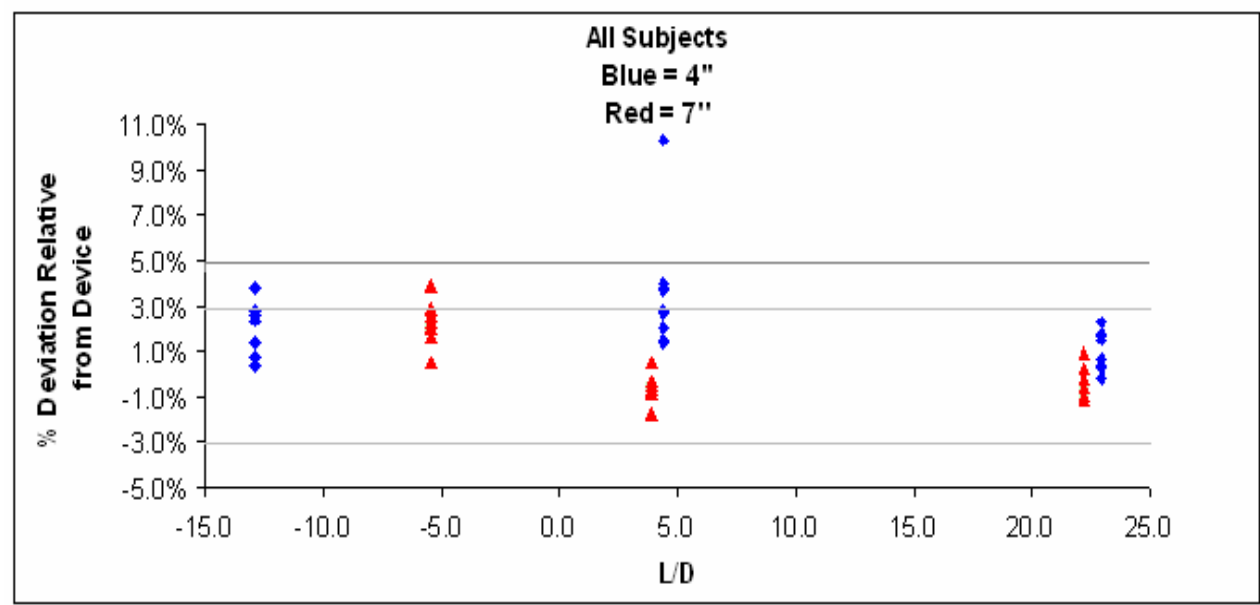

Figure 14: Hand-Held Results Relative from Device - Static Pressure 
Table 4: Results of Mean Traverse Device and All Hand-Held—Static Pressure

\begin{tabular}{|c|c|c|c|c|c|c|}
\hline Subject & $\mathrm{D}$ & $\mathrm{L} / \mathrm{D}$ & Mean & $\begin{array}{c}\text { Standard } \\
\text { Deviation }\end{array}$ & C.V. & $\begin{array}{c}\text { Hand-Held } \\
\text { \% Deviation } \\
\text { From Device }\end{array}$ \\
\hline$\underline{\mathrm{SP}}_{\text {Device }}$ & 3.875 & 23 & 2.93 & 0.027 & $0.9 \%$ & $\mathrm{~N} / \mathrm{A}$ \\
\hline $\mathrm{SP}_{\text {Hand }}$ & 3.875 & 23 & 2.96 & 0.025 & $0.8 \%$ & $1.09 \%$ \\
\hline$\underline{\mathrm{SP}}_{\text {Device }}$ & 6.875 & 22.3 & 3.56 & 0.037 & $1.0 \%$ & $\mathrm{~N} / \mathrm{A}$ \\
\hline$\underline{\mathrm{SP}}_{\text {Hand }}$ & 6.875 & 22.3 & 3.53 & 0.032 & $0.9 \%$ & $-0.61 \%$ \\
\hline$\underline{\mathrm{SP}}_{\text {Device }}$ & 3.875 & 4.4 & 2.48 & 0.090 & $3.6 \%$ & $\mathrm{~N} / \mathrm{A}$ \\
\hline$\underline{\mathrm{SP}}_{\text {Hand }}$ & 3.875 & 4.4 & 2.57 & 0.067 & $2.6 \%$ & $3.59 \%$ \\
\hline$\underline{\mathrm{SP}}_{\text {Device }}$ & 6.875 & 3.9 & 3.33 & 0.047 & $1.4 \%$ & $\mathrm{~N} / \mathrm{A}$ \\
\hline$\underline{\mathrm{SP}}_{\text {Hand }}$ & 6.875 & 3.9 & 3.31 & 0.021 & $0.6 \%$ & $-0.67 \%$ \\
\hline$\underline{\mathrm{PP}}_{\text {Device }}$ & 3.875 & -12.9 & 1.87 & 0.029 & $1.6 \%$ & $\mathrm{~N} / \mathrm{A}$ \\
\hline$\underline{\mathrm{P}}_{\text {Hand }}$ & 3.875 & -12.9 & 1.90 & 0.022 & $1.1 \%$ & $1.81 \%$ \\
\hline$\underline{\mathrm{SP}}_{\text {Device }}$ & 6.875 & -5.4 & 2.23 & 0.035 & $1.6 \%$ & $\mathrm{~N} / \mathrm{A}$ \\
\hline$\underline{\mathrm{SP}}_{\text {Hand }}$ & 6.875 & -5.4 & 2.28 & 0.022 & $1.0 \%$ & $2.07 \%$ \\
\hline & & & & & & \\
\hline
\end{tabular}

\subsection{Errors in Static Pressure}

As shown on Figure 14 and Table 4, the location relative to the elbow and plain duct entry affected the traverse device centerline static pressure results, just as it did with velocity. The coefficient of variation (C.V.) for the most downstream location was $0.9 \%$ with the 4 inch duct and $1.0 \%$ with the 7-inch duct. At both $\mathrm{L} / \mathrm{D}=-12$ and $\mathrm{L} / \mathrm{D}=-5.4$ it was $1.6 \%$. Closest to the elbow, at $\mathrm{L} / \mathrm{D}=4.4$ it was $3.6 \%$ and at $\mathrm{L} / \mathrm{D}=3.9$ it was $1.4 \%$.

The location relative to the elbow and plain duct entry affected the human subject results as well (see Figure 15 and Table 4). The coefficients of variation of the results of the human subjects from the mean of the device results for the most downstream locations $(\mathrm{L} / \mathrm{D}=23.0$ and $\mathrm{L} / \mathrm{D}=22.3$ ) was $0.8 \%$ and $0.9 \%$, respectively. At $\mathrm{L} / \mathrm{D}=-12.9$ and -5.4 it was $1.1 \%$ and $1.0 \%$, respectively. Also, at the locations closest to the elbows, at $\mathrm{L} / \mathrm{D}=4.4$ and 3.9 it was $1.4 \%$, respectively. Again, the deviations from $\mathrm{V}_{\mathrm{Ref}}$ are due to flows not being parallel to the duct, introducing yaw and pitch errors for the Pitot tube. 


\subsection{Discussion of Results}

\subsection{Velocity Pressure Profiles}

The velocity pressure profiles of the individual subjects (see Figures 10.1-10.8) were very similar to the velocity pressure profiles of the means of the traverse device measurements, especially at the most ideal conditions. There was no clear effect of duct diameter on similarity of human subject profiles to device profiles. The VP profile of the 7-inch duct was more erratic than the VP profile of the 4-inch duct. This is due to the fact that the smaller turn ratio of the 6.875 -inch duct $(\mathrm{R} / \mathrm{D}=0.8)$ causes more disturbances to the airflow than larger turn ratio $(\mathrm{R} / \mathrm{D}=1.8)$ of the 3.875 -inch duct's elbow. VP profiles are also somewhat different at the measurement locations upstream from the elbows $\left(\mathrm{L} / \mathrm{D}_{4}\right.$ "'duct $=$ 12.9 and $\mathrm{L} / \mathrm{D}_{7}$ "duct $\left.=-5.4\right)$ due to traverses taking place at different upstream distances relative to the elbow, even though they were equidistant in terms of location relative to the plain ends.

\subsection{Errors in Velocity Measurements Due to Location and Duct Size}

At the same measurement locations, both the device and the human subject measurements would be affected by flows not in-line with the duct. Nearly all of the deviations between human and the Reference results were less than 5\% (see Figure 12). The only deviations over $\pm 5 \%$ were with the 7 -inch duct close to the elbow ( $/ \mathrm{D}=3.9)$, where $11.1 \%$ of the subjects deviated over $\pm 5 \%$. On the other hand, $11.1 \%$ deviated by more than $3 \%$ at $\mathrm{L} / \mathrm{D}=$ -5.4. Also, nearly all of the deviations between human and the traverse device results were less than $5 \%$ (see Figure 13). The only deviations over $\pm 5 \%$ were with the 7 -inch duct close to the elbow $(\mathrm{L} / \mathrm{D}=3.9)$, where $11.1 \%$ of the subjects deviated over $\pm 5 \%$. On the other hand, $11.1 \%$ deviated by more than $3 \%$ at $\mathrm{L} / \mathrm{D}=-5.4$ and 3.9. These deviations may be acceptable for most ventilation practitioners. Industrial Ventilation (ACGIH, 2004) considers errors of 5\% in measurement to be acceptable. From these results, one can conclude that accuracy and repeatability is very good at all locations and best at ideal locations.

Also, at the least ideal locations, the larger duct produced somewhat less repeatable results (Mean C.V. $=1.61 \%$ ) than with the smaller duct (Mean C.V. $=0.94 \%$ ). This is again due to the smaller turning ratio of the elbow of the 7-inch duct.

\subsection{Errors in Static Pressure Measurements Due to Location and Duct Size}

For the static pressure measurements, most of the deviations at all locations between human and the traverse device results were less than 5\% (see Figure 15). The only deviations over $\pm 5 \%$ were with the 4 -inch duct close to the elbow ( $\mathrm{L} / \mathrm{D}=4.4)$, where 1 out of 9 of the subjects deviated over $\pm 5 \%$ and with the 7 -inch duct at $L / D=-5.4$. Also, 1 out of 9 of the subjects deviated by more than $3 \%$ at $\mathrm{L} / \mathrm{D}=-12.9$ and $\mathrm{L} / \mathrm{D}=-5.4$, while 4 out of 9 deviated by at least $3 \%$ at $\mathrm{L} / \mathrm{D}=4.4$. Again, from these results, one can conclude that accuracy and repeatability are very good at all locations and best at ideal locations. 
Also, at the least ideal locations, the smaller duct produces somewhat less repeatable results $($ Mean C.V. $=3.1 \%$ ) than with the larger duct (Mean C.V. $=1.0 \%)$.

One may have expected there to be more deviations between the human subject's measurements and the traverse device measurements due to the traverse device having more control over proper alignment than the subjects. However, a review of literature revealed that it takes at least a $30^{\circ}$ deviation in yaw or pitch to produce errors of $5 \%$ in velocity. Since each subject was instructed on how to align the probe with the airflow, all of the subjects were observed holding the probe at angles that had much less deviation than $30^{\circ}$. In addition, since the hand-held pitot tubes' insertion points were marked and etched, there shouldn't have been significant insertion depth errors. Therefore, the results of the traverse device and the human subjects should be similar, and in fact were.

Location had an expected impact of the results. In this study, there were few errors above $\pm 5 \%$, even at locations closest to the elbow. This was quite similar to previous research (Guffey and Booth, 1999), where at 3D from the elbows, results also seldom exceeded $\pm 5 \%$. Also, as with both this study and the Guffey and Booth study, the airflow error was determined to be a function of the measurement location, with the measurement accuracy improving as the location was moved farther from the elbow.

As expected, the difference in the means of the traverse device and human subject results was a function of duct size. The results were unexpectedly less accurate and repeatable with the 6.875-inch duct instead of the 3.875-inch duct perhaps because of the 6.875-inch duct's smaller relative radius of curvature $(\mathrm{R} / \mathrm{D}=0.8$ compared to 1.8$)$.

Table 5: Deviation of Hand from Device 2-Sided Confidence Intervals: Velocity

\begin{tabular}{|c|c|c|c|c|c|c|c|c|c|}
\hline $\mathrm{D}$ & $\mathrm{L} / \mathrm{D}$ & $\mathrm{U}$ & $\begin{array}{c}\text { Std. Dev. } \\
\text { For C.I. }\end{array}$ & $\underline{\mathrm{V}}_{\mathrm{H}}-\underline{\mathrm{V}}_{\mathrm{D}}$ & $\mathrm{LCL}$ & $\mathrm{UCL}$ & $\left(\underline{\mathrm{V}}_{\mathrm{H}}-\underline{\mathrm{V}}_{\mathrm{D}}\right) / \underline{\mathrm{V}}_{\mathrm{D}}$ & $\mathrm{LCL} \%$ & $\mathrm{UCL} \%$ \\
\hline 3.875 & 23.0 & 7 & 14.7 & -10.6 & -45.3 & 24.2 & $-0.2 \%$ & $-0.9 \%$ & $0.5 \%$ \\
\hline 6.875 & 22.3 & 21 & 15.4 & -40.6 & -72.6 & -8.6 & $-0.8 \%$ & $-1.5 \%$ & $-0.2 \%$ \\
\hline 3.875 & 4.4 & 5 & 29.2 & -17.8 & -92.8 & 57.2 & $-0.4 \%$ & $-1.9 \%$ & $1.2 \%$ \\
\hline 6.875 & 3.9 & 8 & 53.9 & -47.0 & -174.4 & 80.4 & $-0.9 \%$ & $-3.5 \%$ & $1.6 \%$ \\
\hline 3.875 & -12.9 & 7 & 27.3 & -77.0 & -143.8 & -10.2 & $-1.6 \%$ & $-3.0 \%$ & $-0.2 \%$ \\
\hline 6.875 & -5.4 & 10 & 39.7 & 31.8 & -57.9 & 121.6 & $0.7 \%$ & $-1.2 \%$ & $2.5 \%$ \\
\hline
\end{tabular}


Table 6: Deviation of Hand from Reference 2-Sided Confidence Intervals: Velocity

\begin{tabular}{|c|c|c|c|c|c|c|c|c|c|}
\hline $\mathrm{D}$ & $\mathrm{L} / \mathrm{D}$ & $\mathrm{U}$ & $\begin{array}{c}\text { Std. Dev. } \\
\text { For C.I. }\end{array}$ & $\underline{\mathrm{V}}_{\mathrm{H}}-\underline{\mathrm{V}}_{\mathrm{D}}$ & $\mathrm{LCL}$ & $\mathrm{UCL}$ & $\left(\underline{\mathrm{V}}_{\mathrm{H}}-\underline{\mathrm{V}}_{\mathrm{D}}\right) / \underline{\mathrm{V}}_{\mathrm{D}}$ & $\mathrm{LCL} \%$ & $\mathrm{UCL} \%$ \\
\hline 3.875 & 23.0 & 7 & 14.7 & -10.6 & -45.3 & 24.2 & $-0.2 \%$ & $-0.9 \%$ & $0.5 \%$ \\
\hline 6.875 & 22.3 & 21 & 15.4 & -40.6 & -72.6 & -8.6 & $-0.8 \%$ & $-1.5 \%$ & $-0.2 \%$ \\
\hline 3.875 & 4.4 & 9 & 15.9 & 67.3 & 31.4 & 103.2 & $1.4 \%$ & $0.7 \%$ & $2.2 \%$ \\
\hline 6.875 & 3.9 & 19 & 30.1 & 114.7 & 51.4 & 177.9 & $2.4 \%$ & $1.1 \%$ & $3.7 \%$ \\
\hline 3.875 & -12.9 & 14 & 18.3 & -17.5 & -57.0 & 22.0 & $-0.4 \%$ & $-1.2 \%$ & $0.5 \%$ \\
\hline 6.875 & -5.4 & 19 & 25.9 & 30.1 & -24.2 & 84.4 & $0.6 \%$ & $-0.5 \%$ & $1.8 \%$ \\
\hline
\end{tabular}

Table 7: Deviation of Hand from Device 2-Sided Confidence Intervals: Static Pressure

\begin{tabular}{|c|c|c|c|c|c|c|c|c|c|}
\hline $\mathrm{D}$ & $\mathrm{L} / \mathrm{D}$ & $\mathrm{U}$ & $\begin{array}{c}\text { Std. } \\
\text { Dev. } \\
\text { For C.I. }\end{array}$ & $\mathrm{SP}_{\mathrm{H}}-\mathrm{SP}_{\mathrm{D}}$ & $\mathrm{LCL}$ & $\mathrm{UCL}$ & $\left(\mathrm{SP}_{\mathrm{H}}-\mathrm{SP}_{\mathrm{D}}\right) / \mathrm{SP}_{\mathrm{D}}$ & $\mathrm{LCL} \%$ & $\mathrm{UCL} \%$ \\
\hline 3.875 & 23.0 & 6 & 0.0134 & 0.0300 & -0.0029 & 0.0629 & $1.0 \%$ & $-0.1 \%$ & $2.1 \%$ \\
\hline 6.875 & 22.3 & 6 & 0.0182 & -0.0300 & -0.0745 & 0.0145 & $-0.8 \%$ & $-2.1 \%$ & $0.4 \%$ \\
\hline 3.875 & 4.4 & 5 & 0.0432 & 0.0900 & -0.0157 & 0.1957 & $3.6 \%$ & $-0.6 \%$ & $7.9 \%$ \\
\hline 6.875 & 3.9 & 4 & 0.0216 & -0.0200 & -0.0728 & 0.0328 & $-0.6 \%$ & $-2.2 \%$ & $1.0 \%$ \\
\hline 3.875 & -12.9 & 5 & 0.0140 & 0.0300 & -0.0042 & 0.0642 & $1.6 \%$ & $-0.2 \%$ & $3.4 \%$ \\
\hline 6.875 & -5.4 & 5 & 0.0165 & 0.0500 & 0.0097 & 0.0903 & $2.2 \%$ & $0.4 \%$ & $4.1 \%$ \\
\hline
\end{tabular}

Table 5 shows the combined variances of the subject and device velocity results. Variance was calculated using Equation 11. Confidence intervals were computed using Equation 12, with degrees of freedom (v) computed from Equation 13. Also shown are the 2 -sided $95 \%$ confidence intervals about the deviation of subject velocity from the device values at each location (L/D), as well as the deviation of the percentiles from the device values. The results show that all the upper and lower confidence limits were less than $\pm 3.5 \%$.

Table 6 shows the combined variances of the subject and device velocity results. Also shown are the 2-sided 95\% confidence intervals about the deviation of subject velocity from the Reference Values at each location (L/D), as well as the deviation of the percentiles from the Reference Values. The results show that all the upper and lower confidence limits were less than $\pm 3.7 \%$.

Table 7 shows the combined variances of the subject and device static pressure results. The 2-sided 95\% confidence intervals about the deviation of subject velocity from the Reference Values at each location (L/D), as well as the deviation of the percentiles from the Reference Values are also shown. The results show that all the upper and lower confidence limits were less than $\pm 7.9 \%$, and at 5 out of 6 locations, the confidence limits were less than 4.1 . 


$$
\begin{aligned}
& \alpha_{\text {combined }}^{2}=\frac{S_{\text {Device }}^{2}}{n_{\text {Device }}}+\frac{S_{\text {Hand }}^{2}}{n_{\text {Hand }}} \text {. } \\
& \text { Where: } \quad \mathrm{S}_{\text {Device }}{ }^{2}=\text { Device Variance } \\
& \mathrm{S}_{\text {Hand }}{ }^{2}=\text { Hand-Held Variance } \\
& \mathrm{n}_{1}=\text { number of trials, Hand-Held } \\
& \mathrm{n}_{2}=\text { number of trials, Device } \\
& \left(\bar{X}_{1}-\bar{X}_{2}\right)-t_{\alpha / 2} \sqrt{\left(\frac{s_{1}^{2}}{n_{1}}+\frac{S_{2}^{2}}{n_{2}}\right)}<\left(\mu_{1}-\mu_{2}\right)<\left(\bar{X}_{1}-\bar{X}_{2}\right)+t_{\alpha / 2} \sqrt{\left(\frac{S_{1}^{2}}{n_{1}}+\frac{S_{2}^{2}}{n_{2}}\right)}
\end{aligned}
$$

Where: $\quad \underline{X}_{1}=$ Hand-Held Sample Mean

$\underline{X}_{2}=$ Device Sample Mean

$\mathrm{t}_{\alpha / 2}=2.445006$

$\mathrm{S}_{1}{ }^{2}=$ Hand-Held Variance

$\mathrm{S}_{2}{ }^{2}=$ Device Variance

$\mathrm{n}_{1}=$ number of trials, Hand-Held

$\mathrm{n}_{2}=$ number of trials, Device

$\mu_{1}=$ Hand-Held Mean

$\mu_{2}=$ Device Mean

$$
v=\frac{\left(\frac{s_{1}{ }^{2}}{n_{1}}+\frac{s_{2}{ }^{2}}{n_{2}}\right)^{2}}{\frac{\left(\frac{s_{1}{ }^{2}}{n_{1}}\right)^{2}}{n_{1}-1}+\frac{\left(\frac{s_{2}{ }^{2}}{n_{2}}\right)^{2}}{n_{2}-1}}
$$


Where: $\quad v=$ Degrees of Freedom

$$
\begin{aligned}
& \mathrm{S}_{1}{ }^{2}=\text { Hand-Held Variance } \\
& \mathrm{S}_{2}{ }^{2}=\text { Device Variance } \\
& \mathrm{n}_{1}=\text { number of trials, Hand-Held } \\
& \mathrm{n}_{2}=\text { number of trials, Device }
\end{aligned}
$$

Table 8: Deviation of Hand from Device 2-Sided Tolerance Intervals: Velocity

\begin{tabular}{|c|c|c|c|c|c|c|c|c|}
\hline $\mathrm{D}$ & $\mathrm{L} / \mathrm{D}$ & $\mu_{\mathrm{H}}-\mu_{\mathrm{D}}$ & $\mathrm{K}$ & $\mathrm{LTL}$ & $\mathrm{UTL}$ & $\left(\mu_{\mathrm{H}}-\mu_{\mathrm{D}}\right) / \mu_{\mathrm{D}}$ & $\mathrm{LTL} \%$ & $\mathrm{UTL} \%$ \\
\hline 3.875 & 23 & -10.6 & 3.73 & -65.4 & 44.3 & $-0.20 \%$ & $-1.40 \%$ & $0.90 \%$ \\
\hline 6.875 & 22.3 & -40.6 & 2.7 & -82.1 & 0.9 & $-0.80 \%$ & $-1.70 \%$ & $0.00 \%$ \\
\hline 3.875 & 4.4 & -17.8 & 4.41 & -146.6 & 111 & $-0.40 \%$ & $-3.00 \%$ & $2.30 \%$ \\
\hline 6.875 & 3.9 & -47 & 3.53 & -237.3 & 143.3 & $-0.90 \%$ & $-4.80 \%$ & $2.90 \%$ \\
\hline 3.875 & -12.9 & -77 & 3.73 & -178.8 & 24.8 & $-1.60 \%$ & $-3.70 \%$ & $0.50 \%$ \\
\hline 6.875 & -5.4 & 31.8 & 3.26 & -97.4 & 161.1 & $0.70 \%$ & $-2.00 \%$ & $3.40 \%$ \\
\hline
\end{tabular}

Table 9: Deviation of Hand from Reference 2-Sided Tolerance Intervals: Velocity

\begin{tabular}{|c|c|c|c|c|c|c|c|c|}
\hline $\mathrm{D}$ & $\mathrm{L} / \mathrm{D}$ & $\mu_{\mathrm{H}}-\mu_{\mathrm{D}}$ & $\mathrm{K}$ & $\mathrm{LTL}$ & $\mathrm{UTL}$ & $\left(\mu_{\mathrm{H}}-\mu_{\mathrm{D}}\right) / \mu_{\mathrm{D}}$ & $\mathrm{LTL} \%$ & $\mathrm{UTL} \%$ \\
\hline 3.875 & 23 & -10.6 & 3.73 & -65.4 & 44.3 & $-0.20 \%$ & $-1.40 \%$ & $0.90 \%$ \\
\hline 6.875 & 22.3 & -40.6 & 2.7 & -82.1 & 0.9 & $-0.80 \%$ & $-1.70 \%$ & $0.00 \%$ \\
\hline 3.875 & 4.4 & 67.3 & 3.38 & 13.7 & 120.9 & $1.40 \%$ & $0.30 \%$ & $2.50 \%$ \\
\hline 6.875 & 3.9 & 114.7 & 2.78 & 30.8 & 198.5 & $2.40 \%$ & $0.60 \%$ & $4.10 \%$ \\
\hline 3.875 & -12.9 & -17.5 & 2.95 & -71.6 & 36.5 & $-0.40 \%$ & $-1.50 \%$ & $0.80 \%$ \\
\hline 6.875 & -5.4 & 30.1 & 2.75 & -41.3 & 101.5 & $0.60 \%$ & $-0.90 \%$ & $2.10 \%$ \\
\hline
\end{tabular}

Table 10: Deviation of Hand from Device 2-Sided Tolerance Intervals: Static Pressure

\begin{tabular}{|c|c|c|c|c|c|c|c|c|}
\hline $\mathrm{D}$ & $\mathrm{L} / \mathrm{D}$ & $\mu_{\mathrm{H}}-\mu_{\mathrm{D}}$ & $\mathrm{K}$ & $\mathrm{LTL}$ & $\mathrm{UTL}$ & $\left(\mu_{\mathrm{H}}-\mu_{\mathrm{D}}\right) / \mu_{\mathrm{D}}$ & $\mathrm{LTL} \%$ & $\mathrm{UTL} \%$ \\
\hline 3.875 & 23 & 0.03 & 4.007 & -0.0238 & 0.0838 & $1.00 \%$ & $-0.80 \%$ & $2.90 \%$ \\
\hline 6.875 & 22.3 & -0.03 & 4.007 & -0.1029 & 0.0429 & $-0.80 \%$ & $-2.90 \%$ & $1.20 \%$ \\
\hline 3.875 & 4.4 & 0.09 & 4.414 & -0.1008 & 0.2808 & $3.60 \%$ & $-4.10 \%$ & $11.30 \%$ \\
\hline 6.875 & 3.9 & -0.02 & 5.079 & -0.1297 & 0.0897 & $-0.60 \%$ & $-3.90 \%$ & $2.70 \%$ \\
\hline 3.875 & -12.9 & 0.03 & 4.414 & -0.0317 & 0.0917 & $1.60 \%$ & $-1.70 \%$ & $4.90 \%$ \\
\hline 6.875 & -5.4 & 0.05 & 4.414 & -0.0228 & 0.1228 & $2.20 \%$ & $-1.00 \%$ & $5.50 \%$ \\
\hline
\end{tabular}


Table 8 shows the 2 -sided $95 \%, 95 \%$ tolerance intervals (see Equation 14) about the deviation of subject velocity from the Device values at each location (L/D), as well as the deviation of the percentiles from the Device values. The results show that all the upper and lower tolerance limits were less than $\pm 4.8 \%$.

Table 9 shows the 2 -sided $95 \%, 95 \%$ tolerance intervals about the deviation of subject velocity from the Reference Values at each location (L/D), as well as the deviation of the percentiles from the Reference Values. The results show that all the upper and lower tolerance limits were less than $\pm 4.1 \%$.

Table 10 shows the 2 -sided $95 \%, 95 \%$ tolerance intervals about the deviation of subject velocity from the Reference Values at each location (L/D), as well as the deviation of the percentiles from the Reference Values. The results show that one of the upper and lower tolerance limits was $\pm 11.3 \%$. However, the rest of the values were under $\pm 5.5 \%$.

$$
\begin{aligned}
& \mathrm{TL}_{0.95,0.95}=\overline{\mathrm{x}} \pm \mathrm{K}_{\gamma, P, n} \times \mathrm{s} \\
& \text { Where: } \quad \mathrm{TL}_{95 \%, 95 \%, \mathrm{v}}=\text { Tolerance Intervals } \\
& \underline{X}=\text { All Hand-Held Mean }- \text { Reference Mean } \\
& \mathrm{K}=\mathrm{K}_{95 \%, 95 \%, \mathrm{v}} \\
& v=\text { Degrees of Freedom } \\
& \mathrm{S}=\text { Standard Deviation }
\end{aligned}
$$

Table 11: Hypothesis Testing of Velocity: Deviation of Hand from Device

\begin{tabular}{|c|c|c|c|c|c|c|c|c|}
\hline $\mathrm{D}$ & $\mathrm{L} / \mathrm{D}$ & $\mathrm{T}$ & $\mathrm{t}_{2.5 \%}$ & $\mathrm{H}_{0}$ & $\mathrm{H}_{\mathrm{a}}<>$ & $\mathrm{t}_{5.0 \%}$ & $\mathrm{H}_{0}$ & $\mathrm{H}_{\mathrm{a}}<>$ \\
\hline 3.875 & 23 & -0.72 & 2.4 & accept & reject & 1.9 & accept & reject \\
\hline 6.875 & 22.3 & -2.64 & 2.1 & reject & accept & 1.7 & reject & accept \\
\hline 3.875 & 4.4 & -0.61 & 2.6 & accept & reject & 2 & accept & reject \\
\hline 6.875 & 3.9 & -0.87 & 2.4 & accept & reject & 1.9 & accept & reject \\
\hline 3.875 & -12.9 & -2.82 & 2.4 & reject & accept & 1.9 & reject & accept \\
\hline 6.875 & -5.4 & 0.8 & 2.3 & accept & reject & 1.8 & accept & reject \\
\hline
\end{tabular}


Table 12: Hypothesis Testing of Velocity: Deviation of Hand from Reference

\begin{tabular}{|c|c|c|c|c|c|c|c|c|}
\hline $\mathrm{D}$ & $\mathrm{L} / \mathrm{D}$ & $\mathrm{T}$ & $\mathrm{t}_{2.5 \%}$ & $\mathrm{H}_{0}$ & $\mathrm{H}_{\mathrm{a}}<>$ & $\mathrm{t}_{5.0 \%}$ & $\mathrm{H}_{0}$ & $\mathrm{H}_{\mathrm{a}}<>$ \\
\hline 3.875 & 23.0 & -0.72 & 2.4 & accept & reject & 1.9 & accept & reject \\
\hline 6.875 & 22.3 & -2.64 & 2.1 & reject & accept & 1.7 & reject & accept \\
\hline 3.875 & 4.4 & 4.24 & 2.3 & reject & accept & 1.8 & reject & accept \\
\hline 6.875 & 3.9 & 3.81 & 2.1 & reject & accept & 1.7 & reject & accept \\
\hline 3.875 & -12.9 & -0.96 & 2.2 & accept & reject & 1.8 & accept & reject \\
\hline 6.875 & -5.4 & 1.16 & 2.1 & accept & reject & 1.7 & accept & reject \\
\hline
\end{tabular}

Table 13: Hypothesis Testing of Static Pressure: Deviation of Hand from Device

\begin{tabular}{|c|c|c|c|c|c|c|c|c|}
\hline $\mathrm{D}$ & $\mathrm{L} / \mathrm{D}$ & $\mathrm{T}$ & $\mathrm{t}_{2.5 \%}$ & $\mathrm{H}_{0}$ & $\mathrm{H}_{\mathrm{a}}<>$ & $\mathrm{t}_{5.0 \%}$ & $\mathrm{H}_{0}$ & $\mathrm{H}_{\mathrm{a}}<>$ \\
\hline 3.875 & 23.0 & 2.23 & 2.5 & accept & reject & 1.9 & reject & accept \\
\hline 6.875 & 22.3 & -1.65 & 2.6 & accept & reject & 2.0 & accept & reject \\
\hline 3.875 & 4.4 & 2.08 & 2.6 & accept & reject & 2.0 & reject & accept \\
\hline 6.875 & 3.9 & -0.93 & 2.8 & accept & reject & 2.1 & accept & reject \\
\hline 3.875 & -12.9 & 2.15 & 2.6 & accept & reject & 2.0 & reject & accept \\
\hline 6.875 & -5.4 & 3.03 & 2.8 & reject & accept & 2.1 & reject & accept \\
\hline
\end{tabular}


$T=\frac{(\text { Device }- \text { Hand })-0}{\left(\frac{s_{1}{ }^{2}}{n_{1}}+\frac{s_{2}{ }^{2}}{n_{2}}\right)^{0.5}}$

Where: $\quad \mathrm{T}=\mathrm{T}$-Test for Hypothesis

$\mathrm{S}_{1}^{2}=$ Hand-Held Variance

$\mathrm{S}_{2}^{2}=$ Device Variance

$\mathrm{n}_{1}=$ number of trials, Hand

$\mathrm{n}_{2}=$ number of trials, Device

For the relative deviation of hand to device velocity results, the null hypothesis (see Equations 5a-5c) and the alternative hypothesis (see Equations 6a-6d) were tested using Equation 15 and the value of the Student T distributions for $\alpha=5 \%$ and $10 \%$ with the degrees of freedom in Table 5. As shown in Table 11 , for $\mathrm{t}$ at $\alpha / 2=2.5 \%$, the null hypothesis was accepted at $\mathrm{L} / \mathrm{D}=-5.4,3.9,4.4$, and 23.0. The alternate hypothesis was accepted at $\mathrm{L} / \mathrm{D}=-12.9$ and 22.3 , the Reference location for the 6.875-inch duct. For $\mathrm{t}$ at $\alpha / 2=5.0 \%$, the null hypothesis was accepted at $\mathrm{L} / \mathrm{D}=23.0,4.4,3.9$, and -5.4 . The differences in means were significant for the cases where the variances were lowest.

For the relative deviation of hand to Reference value velocity results, the null hypothesis and the alternative hypothesis were tested using Equation 15 and the value of the Student T distributions for $\alpha=5 \%$ and $10 \%$ with the degrees of freedom in Table 6 . As shown in Table 12 , for $\mathrm{t}$ at $\alpha / 2=2.5 \%$, the null hypothesis was accepted at $\mathrm{L} / \mathrm{D}=-5.4,-12.9$, and 23.0. For $\mathrm{t}$ at $\alpha / 2=5.0 \%$, the null hypothesis was accepted at $\mathrm{L} / \mathrm{D}=23,-5.4$, and -12.9 .

For the static pressure results shown in Table 8 , for $\mathrm{t}$ at $\alpha / 2=2.5 \%$, the null hypothesis was accepted at $\mathrm{L} / \mathrm{D}=-12.9,4.4,22.3$, and 23 . For $\mathrm{t}$ at $\alpha / 2=5.0 \%$, the null hypothesis was accepted at $\mathrm{L} / \mathrm{D}=22.3$ and 3.9. 


\subsection{Conclusions}

For the conditions studied, the results of this study show that:

1. Velocity profiles for human subjects and traverse devices were not substantially different.

2. Location had an impact on the accuracy of both the hand-held and device-held Pitot tube measurements, with greater accuracy generally occurring in the ideal air flow conditions.

3. With the 3.875" duct, the results from the traverse device at the least ideal locations ( $\mathrm{L} / \mathrm{D}=4.4$ and 3.9) deviated by as much as $3.4 \%$ from results with the device at the most ideal condition (Reference Values; $\mathrm{L} / \mathrm{D}=23.0$ and 22.3).

4. With the 6.875 " duct, the results from the traverse device at the least ideal locations deviated by as much as $6.2 \%$ from the results with the Reference Values.

5. With the 3.875" duct, the results from the human subjects at the least ideal locations deviated by as much as $3.2 \%$ from the results with the Reference Values.

6. With the $6.875^{\prime}$ ' duct, the results from the human subjects at the least ideal locations deviated by as much as $5.2 \%$ from the results with the Reference Values.

7. Deviations in velocity and static pressure between the measurements of the traverse device and human subjects were small enough to be considered acceptable.

8. In most cases it was the 4-inch duct instead of the 7-inch duct in which the deviation of velocity and static pressure from the hand-held Pitot tube measurements was greater.

9. The confidence intervals for both the deviation from device and deviation from Reference velocity results, all less than $\pm 3.7 \%$, were within $5 \%$ which is typically considered acceptable.

10. At 4 out of 6 locations for the static pressure results, the confidence intervals for the static pressure results were within $5 \%$, with the highest value at $11.3 \%$ and next highest at $5.5 \%$. The high value was the result of one individual's much higher error than the rest of the subjects' measurements at the $\mathrm{L} / \mathrm{D}=4.4$ position (see Figure 14).

11. At 4 out of 6 locations, for both velocity and static pressure, the deviation between the means of the subjects and the device was not significant at $\alpha=5 \%$. It was significant at the two best measurement locations, probably because the lower variances there gave more statistical power to discern small differences.

12. At 3 out of 6 locations, for velocity and static pressure, the deviation between the means of the subjects and the Reference Value was not significant at $\alpha=5 \%$. 


\subsection{Caveats to the Conclusions}

The results apply only to human use of Pitot tubes with insertion points etched onto them. The results may have been radically different without those etch marks since they provide tactile and visual evidence of correct insertion depth.

Since the data was acquired electronically in custom software, the results also were free of the errors that can occur when practitioners record values on paper and later transfer them to a computer spreadsheet. This is especially true since the investigator did all software manipulations, leaving the subjects only to do the actual traverses. A single individual doing both tasks may make more errors.

The elbows used in the construction of the testing apparatus did not have the same turning radius to diameter dimensions. The 3.875-inch duct elbow had a relative radius of curvature $(\mathrm{R} / \mathrm{D})$ of 1.8 while the relative radius of curvature for the 6.875 -inch duct elbow was 0.8 . That difference could have affected results downstream of the elbows, especially at $\mathrm{L} / \mathrm{D}=$ 3.9 and 4.4 .

Similarly, the values of L/D were not same for the locations of the two ducts upstream of the elbow due to space limitations.

It is unknown whether subjects' errors were a result of yaw or pitch deviations. Because of the use of colored etch markings on the Pitot tubes, the subjects' errors were not likely due to insertion point errors.

All measurements included experimental device errors.

When the dampers were set to $4500 \mathrm{FPM}$, using the manometer, errors were introduced do to the device assumptions of NPT $(293.15 \mathrm{~K}, 760 \mathrm{~mm} \mathrm{Hg})$. Actual temperature and barometric pressure was not used to calculate the desired velocity.

One limitation of the study was that device measurements were not taken on the same days as human subject measurements. For that reason, results for humans and devices could not be paired. Paring may have improved the statistical power.

Another limitation of the study is that only 3.875 " and $6.875^{\prime}$ 'duct diameter sizes were used.

Another limitation of this study is that only round and smooth ducts were measured.

One way to improve upon this research is to take more device samples. This would add more confidence to the results of the device held data. 


\subsection{References}

Cheremisinoff, Paul N. and Cheremisinoff, Nicholas P. 1988. Flow Measurement for Engineers and Scientists. New York: Marcel Dekker, inc.

Guffey, Steven E. and Booth, Derrick W. 1999. Comparison of Pitot Traverses Taken at Varying Distances Downstream of Obstructions. American Industrial Hygiene Association Journal: 62:6, 669-679.

Guffey, Steven E. and Booth, Derrick W. 2001. An Evaluation of Industrial Ventilation Troubleshooting Methods in Experimental Systems. American Industrial Hygiene Association Journal: 60:165-174.

American Conference of Governmental Industrial Hygienists 2004. Industrial Ventilation: A Manual of Recommended Practice. Lansing, MI: ACGIH®

ANSI/ASHRAE Standard 111-1988. http://www.ashrae.org

ANSI/ASHRAE Standard 41.2-1987. http://www.ashrae.org

Guffey, Steven (2007). HV_Measurement Software, version 1.042, August 7, 2007. http://www.industrialventilation.net (304) 685-1298

Young, Donald F.; Munson, Bruce R.; and Okiishi, Theodore H. 2001. A Brief Introduction to Fluid Mechanics, Second Edition. New York: John Wiley \& Sons, inc.

Walpole, Ronald E.; Myers, Raymond H.; Myers, Sharon L.; and Ye, Keying 2001. Probability and Statistics for Engineers and Scientists, Seventh Edition. Upper Saddle River, New Jersey: Prentice Hall

Guffey, Steven E. 1990. Simplifying Pitot Traverses Appl. Occup. Environ. Hyg.: 5:95$100 ; 1990$ 
Ower, E and Pankhurst, R.C. 1977. The Measurement of Air Flow, $5^{\text {th }}$ Edition. Oxford, UK: Pergammon Press 


\subsection{Acknowledgements}

I would like to thank my advisor Dr. Steven Guffey for his support and guidance during the course of this research work. I also wish to thank Dr. Kenneth Means, and Dr. Warren Myers, my committee members, for their advice and support. I wish to thank the West Virginia University CEMR Industrial Engineering Department for providing the necessary resources for this research work, as well as the Unites States Air Force for providing me with the necessary funding as well as the opportunity to serve my country. I would also like to thank Raphael Dodrill, Brandon Takacs, Alexa Quinn, Jeff Clark, Joe Sweet, Joshua Maybury, Kristy Harvey, Braxton Lewis, Ahmed El Sotouhy, and Mingyu Wu for their assistance. Above all, I wish to thank God, my family and my friends for their constant support and enabling of my successes in life.

Christopher D. Judy 


\section{Appendix A: Instrument Calibration}

The psychrometer thermometers were calibrated on Oct. 30, 2007. Also, the manometer was calibrated on Oct. 31, 2007. The results are shown in the following tables and figures. The results are also shown. All calibrated instruments were within acceptable standards.

Dry-Bulb Thermometer Calibration

\begin{tabular}{|c|c|c|}
\hline $\begin{array}{c}\text { Time } \\
(\text { Min })\end{array}$ & $\begin{array}{c}\text { Cal } \\
\left({ }^{\circ} \mathrm{C}\right)\end{array}$ & $\begin{array}{c}\text { DBT } \\
\left({ }^{\circ} \mathrm{C}\right)\end{array}$ \\
\hline 15 & 22.9 & 23 \\
\hline 30 & 22.7 & 22.75 \\
\hline 45 & 22.5 & 22.5 \\
\hline 60 & 22.3 & 22.5 \\
\hline 75 & 22.3 & 22.5 \\
\hline 90 & 22.4 & 22.5 \\
\hline 105 & 22.3 & 22.5 \\
\hline 120 & 22.3 & 22.5 \\
\hline
\end{tabular}

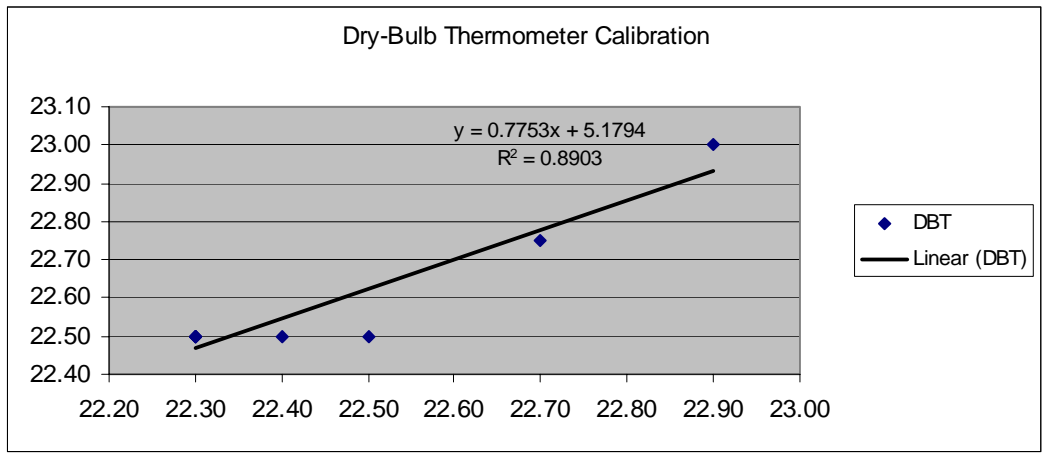

Wet-Bulb Thermometer Calibration

\begin{tabular}{|c|c|c|}
\hline $\begin{array}{c}\text { Time } \\
(\text { Min })\end{array}$ & $\begin{array}{c}\text { Cal } \\
\left({ }^{\circ} \mathrm{C}\right)\end{array}$ & $\begin{array}{c}\text { DBT } \\
\left({ }^{\circ} \mathrm{C}\right)\end{array}$ \\
\hline 15 & 22.70 & 23.00 \\
\hline 30 & 22.80 & 23.00 \\
\hline 45 & 23.00 & 23.25 \\
\hline 60 & 23.00 & 23.25 \\
\hline 75 & 22.80 & 23.00 \\
\hline 90 & 22.70 & 23.00 \\
\hline 105 & 22.80 & 23.00 \\
\hline 120 & 22.70 & 23.00 \\
\hline
\end{tabular}




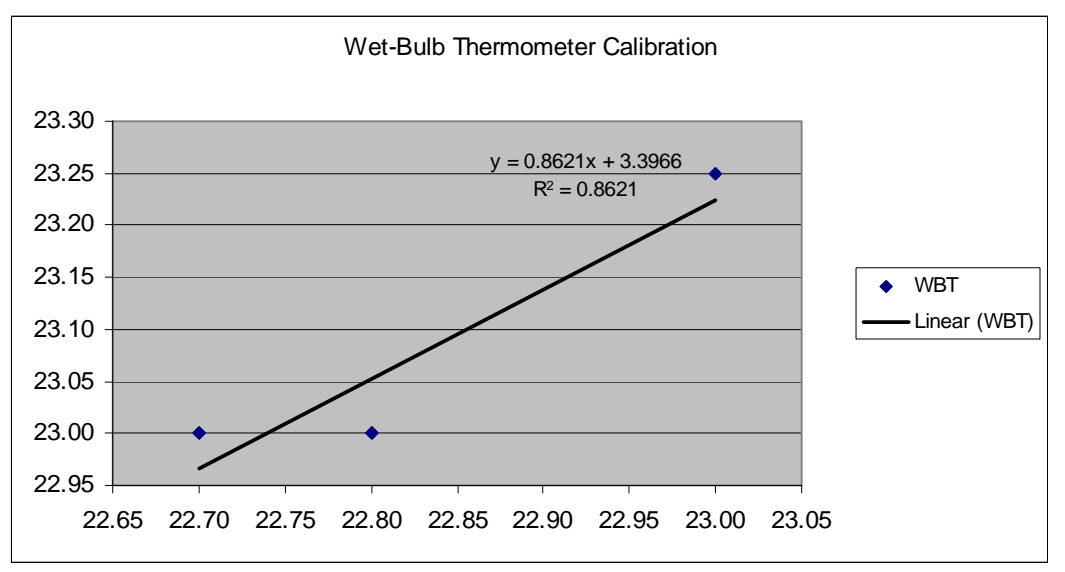

PVM 100 Calibration

\begin{tabular}{|c|c|}
\hline Hook ("WG) & PVM ("WG) \\
\hline 0 & 0 \\
\hline 0.1 & 0.102 \\
\hline 0.5 & 0.495 \\
\hline 1 & 0.998 \\
\hline 1.5 & 1.498 \\
\hline 2 & 2.009 \\
\hline 2.5 & 2.503 \\
\hline 3 & 3.01 \\
\hline 3.5 & 3.509 \\
\hline 4 & 3.992 \\
\hline
\end{tabular}

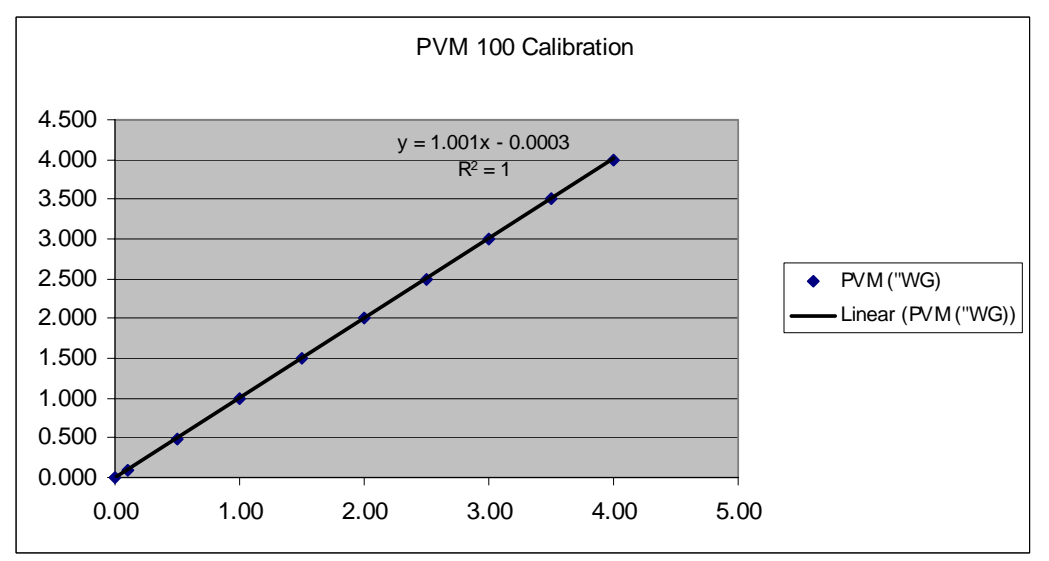




\section{Appendix B: Results}

Estimate of Variance: Velocity

\begin{tabular}{|c|c|c|c|c|c|}
\hline & & \multicolumn{2}{|c|}{ All Subjects } & \multicolumn{2}{c|}{ Device } \\
\hline $\mathrm{D}$ & $\mathrm{L} / \mathrm{D}$ & $\mathrm{s}_{1}{ }_{1} / \mathrm{n}$ & $\mathrm{n}$ & $\mathrm{s}_{2}{ }_{2} / \mathrm{n}$ & $\mathrm{n}$ \\
\hline 3.875 & -12.9 & 175 & 18 & 569 & 5 \\
\hline 6.875 & 4.4 & 92 & 18 & 759 & 5 \\
\hline 3.875 & 23.0 & 56 & 18 & 159 & 5 \\
\hline 6.875 & -5.4 & 619 & 18 & 954 & 5 \\
\hline 3.875 & 3.9 & 853 & 18 & 2050 & 5 \\
\hline 6.875 & 22.3 & 182 & 18 & 54 & 5 \\
\hline
\end{tabular}

Estimate of Variance: Static Pressure

\begin{tabular}{|c|c|c|c|c|c|}
\hline & & \multicolumn{2}{|c|}{ All Subjects } & \multicolumn{2}{c|}{ Device } \\
\hline $\mathrm{D}$ & $\mathrm{L} / \mathrm{D}$ & $\mathrm{s}^{2}{ }_{1} / \mathrm{n}$ & $\mathrm{n}$ & $\mathrm{s}^{2}{ }_{2} / \mathrm{n}$ & $\mathrm{n}$ \\
\hline 3.875 & -12.9 & $2.69 \mathrm{E}-05$ & 18 & $1.68 \mathrm{E}-04$ & 5 \\
\hline 6.875 & -5.4 & $2.69 \mathrm{E}-05$ & 18 & $2.45 \mathrm{E}-04$ & 5 \\
\hline 3.875 & 3.9 & $2.45 \mathrm{E}-04$ & 18 & $4.42 \mathrm{E}-04$ & 5 \\
\hline 6.875 & 4.4 & $2.49 \mathrm{E}-04$ & 18 & $1.62 \mathrm{E}-03$ & 5 \\
\hline 3.875 & 22.3 & $5.69 \mathrm{E}-05$ & 18 & $2.74 \mathrm{E}-04$ & 5 \\
\hline 6.875 & 23.0 & $3.47 \mathrm{E}-05$ & 18 & $1.46 \mathrm{E}-04$ & 5 \\
\hline
\end{tabular}

